\title{
Article \\ A Comprehensive Molecular and Clinical Analysis of the piRNA Pathway Genes in Ovarian Cancer
}

\author{
Eunice Lee $^{1}\left(\mathbb{D}\right.$, Noor A. Lokman ${ }^{2,3}$, Martin K. Oehler ${ }^{2,3,4}$, Carmela Ricciardelli ${ }^{2, *,+}$ (1) \\ and Frank Grutzner ${ }^{1, *,+}$ \\ 1 Department of Molecular and Biomedical Sciences, Robinson Research Institute, University of Adelaide, \\ Adelaide, SA 5000, Australia; eunicehsiuyee.lee@adelaide.edu.au \\ 2 Discipline of Obstetrics and Gynaecology, Robinson Research Institute, Adelaide Medical School, \\ University of Adelaide, Adelaide, SA 5000, Australia; noor.lokman@adelaide.edu.au (N.A.L.); \\ martin.oehler@adelaide.edu.au (M.K.O.) \\ 3 Future Industries Institute, University of South Australia, Mawson Lakes, SA 5095, Australia \\ 4 Department of Gynaecological Oncology, Royal Adelaide Hospital, Adelaide, SA 5005, Australia \\ * Correspondence: carmela.ricciardelli@adelaide.edu.au (C.R.); frank.grutzner@adelaide.edu.au (F.G.); \\ Tel.: +61-8-8313-8255 (C.R.); +61-8-8313-4812 (F.G.) \\ + Authors contributed equally to the work.
}

Citation: Lee, E.; Lokman, N.A.; Oehler, M.K.; Ricciardelli, C.; Grutzner, F. A Comprehensive Molecular and Clinical Analysis of the piRNA Pathway Genes in Ovarian Cancer. Cancers 2021, 13, 4. https:// dx.doi.org/10.3390/cancers13010004

Received: 15 October 2020

Accepted: 18 December 2020

Published: 22 December 2020

Publisher's Note: MDPI stays neutral with regard to jurisdictional claims in published maps and institutional affiliations.

Copyright: (c) 2020 by the authors. Licensee MDPI, Basel, Switzerland. This article is an open access article distributed under the terms and conditions of the Creative Commons Attribution (CC BY) license (https: / / creativecommons.org/ licenses/by/4.0/).
Simple Summary: Although ovarian cancer (OC) is one of the most lethal gynecological cancers, its development and progression remain poorly understood. The piRNA pathway is important for transposon defense and genome stability. piRNA maturation and function involve a number of genes known as the piRNA pathway genes. These genes have recently been implicated in cancer development and progression but information about their role in OC is limited. Our work aimed to provide a better understanding of the roles of piRNA pathway genes in OC. Through analyzing changes in the abundance of 10 piRNA pathway genes, we discovered gene expression differences in benign vs. cancer, chemosensitive vs. chemoresistant and post hormone treatment in OC samples and cells. Furthermore, we observed the differential effects of these genes on patient survival and OC cell invasion. Overall, this work supports a role of the piRNA pathway genes in OC progression and encourages further study of their clinical relevance.

Abstract: Ovarian cancer (OC) is one of the most lethal gynecological malignancies, yet molecular mechanisms underlying its origin and progression remain poorly understood. With increasing reports of piRNA pathway deregulation in various cancers, we aimed to better understand its role in OC through a comprehensive analysis of key genes: PIWIL1-4, DDX4, HENMT1, MAEL, PLD6, TDRD1,9 and mutants of PIWIL1 (P1D17) and PIWIL2 (PL2L60). High-throughput qRT-PCR $(n=45)$ and CSIOVDB $(n=3431)$ showed differential gene expression when comparing benign ovarian tumors, low grade OC and high grade serous OC (HGSOC). Significant correlation of disparate piRNA pathway gene expression levels with better progression free, post-progression free and overall survival suggests a complex role of this pathway in OC. We discovered PIWIL3 expression in chemosensitive but not chemoresistant primary HGSOC cells, providing a potential target against chemoresistant disease. As a first, we revealed that follicle stimulating hormone increased PIWIL2 expression in OV-90 cells. PIWIL1, P1 17 , PIWIL2, $P L 2 L 60$ and MAEL overexpression in vitro and in vivo decreased motility and invasion of OVCAR-3 and OV-90 cells. Interestingly, P1 17 and PL2L60, induced increased motility and invasion compared to PIWIL1 and PIWIL2. Our results in HGSOC highlight the intricate role piRNA pathway genes play in the development of malignant neoplasms.

Keywords: ovarian cancer; piRNA pathway; patient survival; invasion; follicle stimulating hormone; chemoresistance; therapeutic targets 


\section{Introduction}

Ovarian cancer (OC) is one of the leading causes of death in women worldwide where 184,799 deaths were projected in 2018. This was the second highest mortality among all gynecological cancers [1]. Due to unspecific symptoms and lack of early detection, $\mathrm{OC}$ is most commonly diagnosed at an advanced stage and subsequently has very poor prognosis [2,3]. It has been hypothesized that the number of ovulation cycles correlates with the risk of developing $\mathrm{OC}$ and that hormones such as follicle stimulating hormone (FSH) and luteinizing hormone (LH) might be involved in the process and induce malignant transformation $[4,5]$. While incessant ovulation is considered a risk factor, this theory is still controversial $[6,7]$.

OC consists of epithelial ovarian cancers (EOC) $(90 \%)$ which include subtypes serous, mucinous, clear cell and endometroid. Nonepithelial ovarian cancers $(10 \%)$ include smallcell carcinomas and sarcomas and malignancies originating from germ or sex cord-stromal cells [8,9]. HGSOC is known for its highly heterogeneous nature, chromosomal instability and high rates of chemoresistance where mutations in the TP53 gene occur in a majority of HGSOC samples, more than any other cancer [10-14]. While mutations in tumor suppressor TP53 have been postulated as the driver of HGSOC, the etiology, subsequent progression and development of chemoresistance are poorly understood $[15,16]$. OC is classified through FIGO staging (stages I-IV) and grading (grades 1-3). In the serous OC context, low grade (grade 1) and high grade (grades 2 and 3 ) are classified as two separate diseases with different underlying molecular pathology and clinical behavior $[11,17,18]$. Tumor malignancies are often linked to a large number of genes and their associated mutants as seen in OC $[12,19,20]$. With the origin and development of OC still under much discussion, the emergence of deregulated piRNA pathway in cancer has led to a few studies investigating their involvement in OC development [6,21-26].

The piRNA pathway consists of piRNAs (small noncoding RNAs (ncRNAs)) and a growing list of associated pathway genes which are involved in the biogenesis of piRNAs [27-29]. The core biogenesis pathway genes, the PIWIL genes (PIWIL1-4), are essential in ensuring the maturation of piRNAs through their involvement in either the primary or secondary biogenesis pathway [30]. To do this, PIWILs utilize their three main domains known as PAZ, MID and PIWI. These domains mainly function in binding the $3^{\prime}$ end of piRNAs, $5^{\prime}$ end of piRNAs and having endonuclease activity, respectively [31-33]. On top of the PIWIL genes, there is a myriad of pathway genes including DDX4, HENMT1, $M A E L, P L D 6, T D R D 1$ and TDRD9. A more detailed list of pathway genes and their respective functions in piRNA biogenesis was recently reviewed by Ozata, Gainetdinov, Zoch, $\mathrm{O}^{\prime}$ Carroll and Zamore [28]. The piRNA pathway was originally discovered in gonads as a mechanism to control expression of transposable elements (TEs) [34,35]. In addition to having crucial roles in the production of mature piRNAs, the pathway genes can also work in tandem or independently of each other to aid piRNAs in the execution of TE repression [36-39]. One method is through the fascinating secondary biogenesis pathway where PIWIL2 and PIWIL4 convert TEs into piRNAs, generating a multitude of piRNA species while destroying TEs $[36,40,41]$. Since the discovery of the piRNA pathway, its roles beyond TE repression has steadily increased especially after reports of its deregulation in cancer [42-44].

piRNAs and piRNA pathway genes are increasingly discovered to be involved in various aspects of cancer development and progression [43]. Some of these pathway genes (PIWIL1, PIWIL2, TDRD1 and MAEL) are categorized as cancer/testis genes due to their restricted expression in testis but in recent years, have been observed to be aberrantly expressed in multiple cancers [43-46]. The functions of these genes go beyond the piRNA pathway and include regulating cell motility, invasion, proliferation and apoptosis which are hallmarks of cancer progression and malignancy [19,24,43,47-49]. Additionally, cancer specific mutations have been revealed including a PIWIL1 mutant (P1 17$)$ which lacks an exon 17 and a PIWIL2 mutant (PL2L60) with a truncated PAZ domain $[25,50]$. The $P 1 \Delta 17$ transcript was only present in malignant HGSOC and was proposed to have a premature 
stop codon with a truncated PIWI domain in its protein form [25]. Upon discovery of PL2L60 in mouse testis, it was then found to be the predominant form of PIWIL2 in precancerous stem cells where its expression associates with the antiapoptotic STAT-3/BCL2 pathway [50].

Here, we present extensive expression screening of piRNA pathway genes in early and late stage HGSOC tumors, benign serous cystadenoma as well as low grade OC tumors (workflow diagram, Figure 1). We assessed their potential link to treatment response (chemosensitivity versus chemoresistance), progression-free survival (PFS), post progression-free survival (PPFS) and overall survival (OS) in HGSOC patients. We also determined if there was a change in PIWIL2 expression after OC cells were treated with FSH and LH, individually and in combination. Finally, we assessed whether overexpression of the pathway genes and mutants (P1 17 and PL2L60) affected the motility and invasion of HGSOC in vitro and in vivo. This work highlights that the piRNA pathway may function differently in different cancers and provides novel insights into its role in OC.

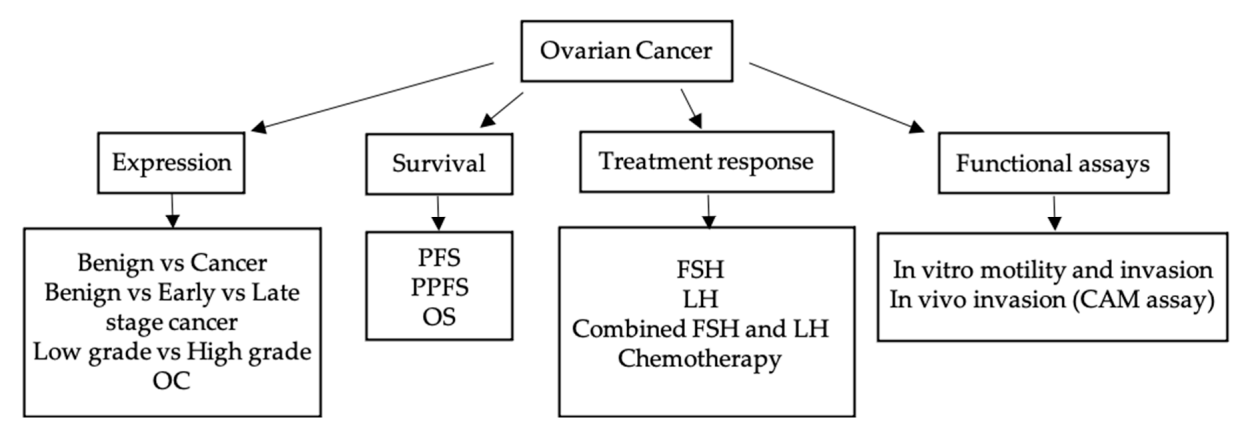

Figure 1. Workflow diagram of this study showing analysis performed for investigating expression differences and effects of the piRNA pathway genes in multiple aspects of OC.

\section{Results}

\subsection{Differential Expression of piRNA Pathway Genes Occurs between Benign and Malignant HGSOC Tissue Samples}

A growing list of piRNA pathway genes are being implicated in cancer but only limited studies address their potential role in OC. We profiled the mRNA expression levels of 10 piRNA pathway genes in benign serous cystadenoma $(n=16)$, early and late stage HGSOC tissue samples $(n=29)$ (Figure 2). Interestingly, we observed that the PIWIL genes had dissimilar trends of expression in benign and cancerous tumors. PIWIL1 had significantly higher expression (Figure 2a), while PIWIL2 expression was significantly lower in cancerous tumors (early and late stage) as compared to benign tumors (Figure 2b). Most tumors had no PIWIL3 expression (Figure 2c) whereas PIWIL4 had significantly lower expression in early stage HGSOC samples but not late stage when compared to benign tumors (Figure 2d).

RNA helicase DDX4 had no significant difference in expression when comparing benign to cancerous tumors but there was an increasing trend in expression between early and late stage HGSOC samples (Figure 2e) [51]. RNA methyltransferase HENMT1 (Figure 2f) and spindle class gene MAEL (Figure 2g) both had significantly increased expression in HGSOC tumors compared to benign tumors [52,53]. While HENMT1 expression was significantly increased between benign and early and late stage tumors, MAEL expression was only significantly increased between benign and late stage tumors. Phospholipase PLD6 had similar expression levels in benign and cancerous tumors (Figure 2h) [54]. Methylarginine binding genes TDRD1 (Figure 2i) and TDRD9 (Figure 2j), had overall low expression in HGSOC and benign tumors [55]. TDRD1 expression was reduced in HGSOC compared to benign tumors and expression was significantly lower in late stage tumors compared to benign tumors. 

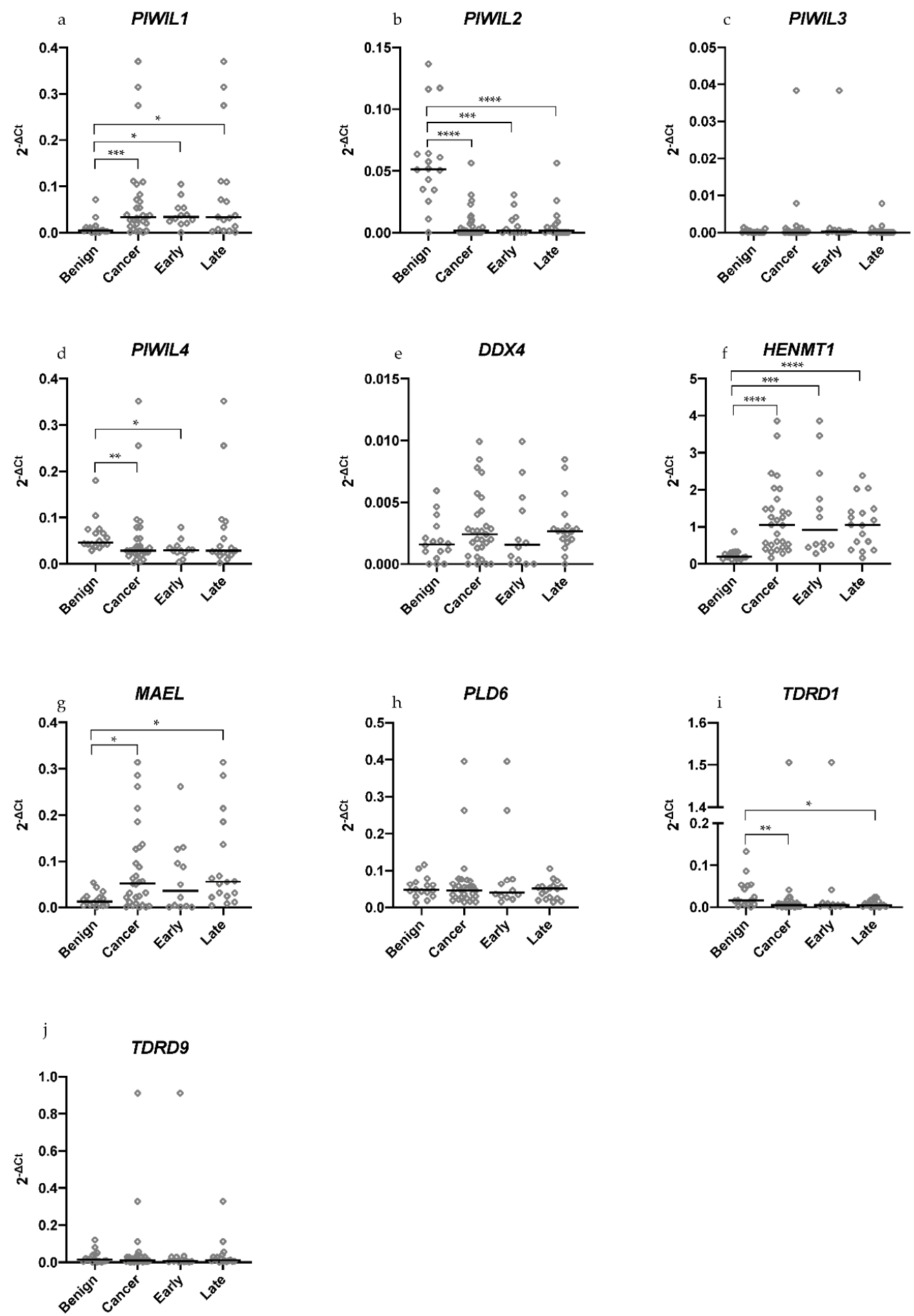

Figure 2. piRNA pathway gene expression in benign serous cystadenoma and high grade serous ovarian cancer (HGSOC) tumors. (a-d) Among the 4 PIWIL genes, only PIWIL3 had no significant difference between benign and cancerous tumors. PIWIL1 had increased expression while PIWIL2 and PIWIL4 had decreased expression between benign and cancerous samples. (e-j) Comparing expression of benign to cancerous tumors, HENMT1 and MAEL had significantly increased expression while TDRD1 expression was significantly decreased. DDX4, PLD6 and TDRD9 presented similar expression levels across benign and cancerous tumors. All Ct scores were normalized to the geomean of housekeepers, TBP and GUSB. A median line was used to plot the respective dataset. Benign $(n=16)$, cancer (early and late HGSOC, $n=29)$, early HGSOC (stages $1,2, n=12$ ) and late HGSOC (stage 3, $n=17$ ). Statistical tests Mann-Whitney U was used to analyze benign versus cancer while Kruskal-Wallis (non-normal distribution) or one-way ANOVA (normal distribution) were used accordingly when comparing expression differences in benign, early and late stage HGSOC. ${ }^{*} p<0.05 ;{ }^{* *} p<0.005 ;{ }^{* * *} p<0.0005 ;{ }^{* * *} p<0.0001$. 


\section{2. piRNA Pathway Genes are Differentially Expressed in Low Grade and High Grade Ovarian Cancer (All Subtypes)}

Following the differential expression observed in HGSOC staging, we next investigated if the piRNA pathway genes had distinct expression levels in low grade (G1) versus high grade (G2, G3) disease in OC (Figure 3). PIWIL1 and PIWIL3 had significantly lower expression in high grade compared to G1 (Figure 3a,c). PIWIL2 and PIWIL4 expression was not different between low grade and high grade (Figure $3 b, d$ ). We also observed similar expression levels for DDX4, MAEL and TDRD9 across low and high grade OC (Figure 3e,g,j). In contrast, HENMT1 expression was significantly higher in G2 and G3 compared to G1 (Figure 3f). Of note, HENMT1 expression was significantly increased from G2 to G3 (Figure 3f). PLD6 and TDRD1 expression were significantly lower in G2 and G3 compared to G1 (Figure 3h,i).
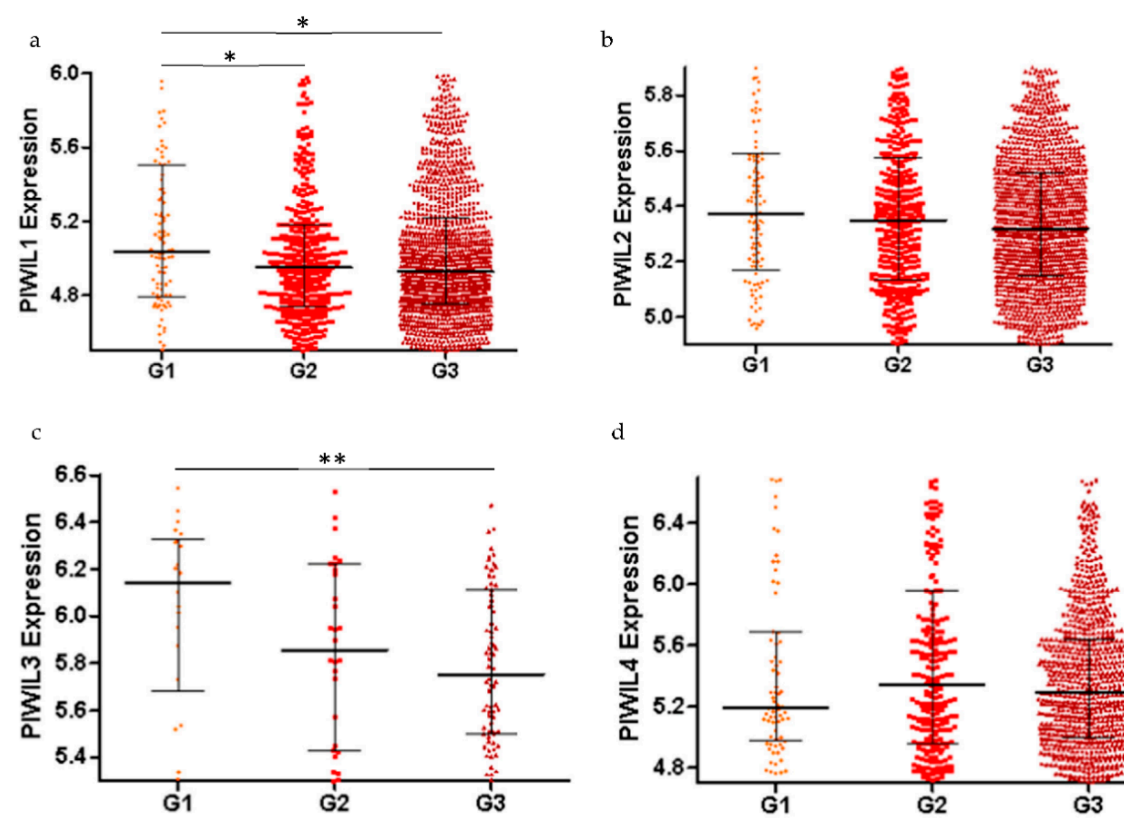

d
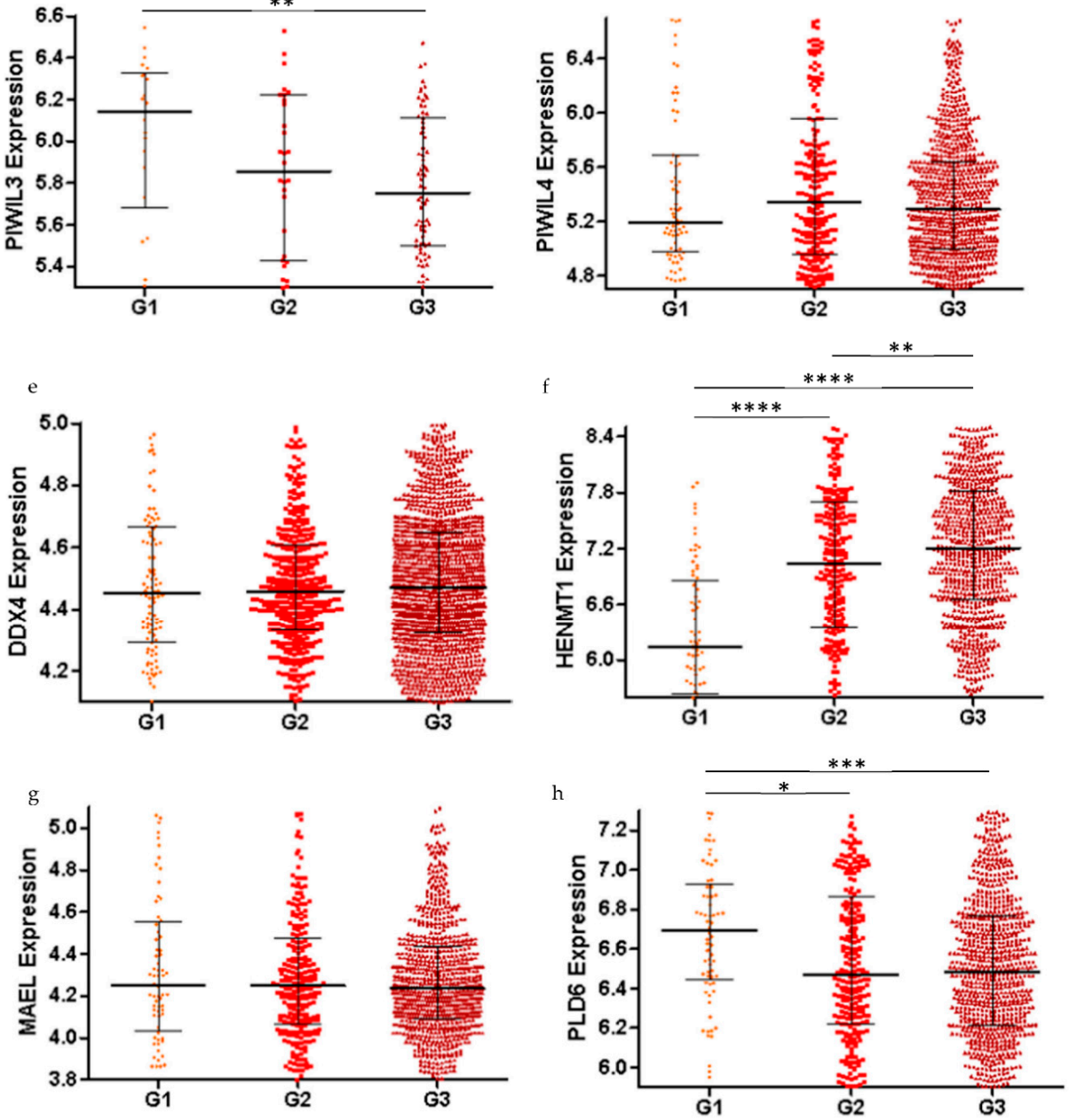

Figure 3. Cont. 

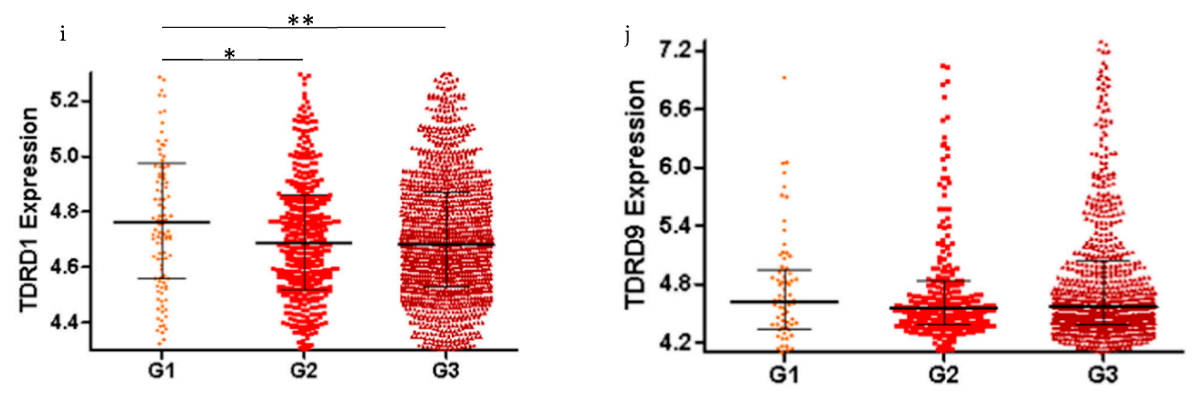

Figure 3. Using the CSIOVDB public microarray database $(n=3431)$ to determine piRNA pathway gene expression in grades 1, 2 and 3 (G1, G2 and G3) of all ovarian cancer subtypes. (a-d) Among the 4 PIWIL genes, PIWIL1 and PIWIL3 showed significantly lower expression in the high grade (G2/G3) disease as compared to low grade (G1). PIWIL2 and PIWIL4 had similar expression levels in G1, G2 and G3 ovarian cancer samples. (e,g-j) PLD6 and TDRD1 also had significantly decreased expression when comparing low grade to high grade. DDX4, MAEL and TDRD9 had no significant difference in expression across G1, G2 and G3. (f) HENMT1, in contrast, had significantly higher expression in G2 and G3 as compared to G1. Mann-Whitney U test was used to assess significance. ${ }^{*} p<0.05$; ** $p<0.005 ;{ }^{* * *} p<0.0005 ;{ }^{* * * *} p<0.0001$.

\subsection{The Level of piRNA Pathway Gene Expression Is Associated with HGSOC Patient Overall and Progression Free Survival}

Next, we correlated expression of piRNA pathway genes with early and advanced stage patient outcome using the Kaplan-Meier (KM) online plotter which is based on data from large public microarray databases (Table 1). With the exception of HENMT1 which did not significantly correlate with PFS, PPFS or OS, all other genes were associated with HGSOC patient outcome. High PIWIL1 expression was significantly associated with improved PPFS and OS in both early $(p=0.034 ; p=0.017)$ and late $(p=0.0002 ; p=0.00033)$ stage HGSOC patients. Conversely, low PIWIL2 and PIWIL4 expression were significantly associated with increased PFS in late stage $(p=0.0051 ; p=0.015)$ patients. HGSOC patients with low PIWIL2 expression also had significantly increased PPFS ( $p=0.048)$.

Although high expression of DDX4 was associated with longer PFS $(p=0.046)$, low DDX4 was associated with improved OS $(p=0.035)$ in early stage HGSOC patients. Low MAEL expression in both early $(p=0.0037)$ and late $(p=0.048)$ stage HGSOC patients was associated with increased PFS whereas high expression was associated significantly with increased OS $(p=0.041)$ in only late stage HGSOC patients. Low PLD6 expression was significantly associated with increased OS $(p=0.027)$ in late stage patients. Early stage HGSOC patients with high TDRD1 expression had very significantly longer PFS $(p=0.000042)$ while late stage patients with low TDRD9 expression had significantly better PFS $(p=0.05)$.

\subsection{PIWIL3 Is Expressed in Chemosensitive Primary HGSOC Cells but not in Chemoresistant Primary HGSOC Cells}

Recognizing that chemoresistance is a major problem for treatment in OC, we evaluated piRNA pathway gene expression in chemosensitive and chemoresistant HGSOC patient-derived primary cells in search of a potential chemoresistant treatment target [2]. We found that PIWIL1 and PIWIL2 had a similar expression pattern in chemosensitive and chemoresistant primary HGSOC cells (Figure 4a,b). Only PIWIL3 expression was observed to be significantly increased in chemosensitive primary cells (Figure 4c). PIWIL4, DDX4, MAEL, TDRD1 and TDRD9 expression decreased in chemoresistant primary cells, but those changes were not significant (Figure 4d,e,g,i,j). HENMT1 showed no difference in expression while PLD6 expression had a slight increase in chemoresistant cells compared to chemosensitive cells, albeit without significance (Figure $4 \mathrm{f}, \mathrm{h}$ ). 
Table 1. Kaplan-Meier survival analysis of high grade serous ovarian cancer (HGSOC) patients according to piRNA pathway gene expression levels.

(a) Early Stage HGSOC Patients (FIGO Stage I and II)

\begin{tabular}{|c|c|c|c|c|c|c|c|c|c|}
\hline \multirow{2}{*}{$\begin{array}{c}\text { piRNA Pathway } \\
\text { Genes }\end{array}$} & \multicolumn{3}{|c|}{ Progression Free Survival } & \multicolumn{3}{|c|}{ Post Progression Survival } & \multicolumn{3}{|c|}{ Overall Survival } \\
\hline & HR & $95 \%$ CI & $p$-Value & HR & $95 \%$ CI & $p$-Value & HR & $95 \%$ CI & $p$-Value \\
\hline PIWIL1 & 0.66 & $0.31-1.4$ & 0.27 & 0.33 & $0.11-0.96$ & 0.034 & 0.37 & $0.16-0.86$ & 0.017 \\
\hline PIWIL2 & 0.55 & $0.25-1.21$ & 0.13 & 3.64 & $0.47-28.09$ & 0.18 & 2.03 & $0.87-4.78$ & 0.097 \\
\hline PIWIL4 & 2 & $0.74-5.4$ & 0.16 & 0.17 & $0.02-1.48$ & 0.07 & 0.66 & $0.21-2.1$ & 0.48 \\
\hline$D D X 4$ & 0.45 & $0.2-1.01$ & 0.046 & 0.41 & $0.09-1.88$ & 0.24 & 3.51 & $1.02-12.09$ & 0.035 \\
\hline HENMT1 & 2.79 & $0.96-8.15$ & 0.051 & 4.47 & $0.81-24.55$ & 0.059 & 2.33 & $0.7-7.72$ & 0.15 \\
\hline$M A E L$ & 4.75 & $1.5-15.08$ & 0.0037 & 2.78 & $0.32-24.36$ & 0.34 & 2.54 & $0.74-8.69$ & 0.12 \\
\hline PLD6 & 0.42 & $0.14-1.29$ & 0.12 & 0.3 & $0.04-2.23$ & 0.21 & 3.4 & $0.74-15.61$ & 0.094 \\
\hline TDRD1 & 0.24 & $0.11-0.5$ & 0.000042 & 0.44 & $0.14-1.38$ & 0.15 & 0.49 & $0.21-1.17$ & 0.1 \\
\hline TDRD9 & 0.6 & $0.2-1.84$ & 0.37 & 3.11 & $0.59-16.26$ & 0.16 & 0.6 & $0.17-2.08$ & 0.42 \\
\hline \multicolumn{10}{|c|}{ (b) Late Stage HGSOC Patients (FIGO Stage III) } \\
\hline PIWIL1 & 0.91 & $0.76-1.08$ & 0.27 & 0.68 & $0.55-0.83$ & 0.0002 & 0.7 & $0.58-0.85$ & 0.00033 \\
\hline PIWIL2 & 1.32 & $1.09-1.61$ & 0.0051 & 1.27 & $1-1.6$ & 0.048 & 0.88 & $0.73-1.06$ & 0.18 \\
\hline PIWIL4 & 1.35 & $1.06-1.72$ & 0.015 & 1.25 & $0.94-1.68$ & 0.13 & 1.3 & $0.98-1.74$ & 0.067 \\
\hline DDX4 & 0.91 & $0.76-1.09$ & 0.3 & 1.17 & $0.96-1.43$ & 0.11 & 0.88 & $0.72-1.07$ & 0.19 \\
\hline HENMT1 & 1.17 & $0.9-1.52$ & 0.23 & 1.2 & $0.87-1.66$ & 0.27 & 1.28 & $0.93-1.74$ & 0.13 \\
\hline$M A E L$ & 1.27 & $1-1.62$ & 0.048 & 0.77 & $0.56-1.05$ & 0.093 & 0.72 & $0.53-0.99$ & 0.041 \\
\hline PLD6 & 1.19 & $0.94-1.51$ & 0.15 & 1.18 & $0.88-1.59$ & 0.27 & 1.38 & $1.04-1.84$ & 0.027 \\
\hline TDRD1 & 0.89 & $0.74-1.08$ & 0.24 & 0.84 & $0.67-1.05$ & 0.14 & 0.83 & 0.69-1.01 & 0.061 \\
\hline TDRD9 & 1.27 & $1-1.61$ & 0.05 & 0.82 & $0.6-1.11$ & 0.2 & 1.18 & $0.89-1.56$ & 0.24 \\
\hline
\end{tabular}

Sample size of early stage HGSOC patients assessed for PFS $(n=84)$, PPFS $(n=32)$ and OS $(n=87)$; late stage HGSOC patients for PFS $(n=807)$, PPFS $(n=573)$ and OS $(n=836)$. HR > 1: low expression confers better outcome; HR < 1: high expression confers better outcome. $\mathrm{HR}=$ hazard ratio $; 95 \% \mathrm{CI}=95 \%$ confidence interval; $p<0.05=$ significant. $\mathrm{HR}, 95 \% \mathrm{CI}$ and $p$-values in bold are significant.

\subsection{PIWIL2 Expression Increased upon FSH Treatment in OV-90 Cells}

As OC development has been linked to hormones, we were interested to see if the piRNA pathway genes are affected by hormones. RT-PCR of OV-90 cells after treatment with different concentrations of gonadotropins, FSH and LH, showed increased PIWIL2 expression (Figure 5a). Further analysis using qRT-PCR showed specifically a higher dose of FSH (100 mIU / mL) significantly increased PIWIL2 expression (Figure $5 b)$. While both treatment doses of LH ( 25 and $50 \mathrm{mIU} / \mathrm{mL}$ ) elevated PIWIL2 expression, this change was not significant (Figure 5b). Interestingly, PIWIL2 expression after treatment with both LH and FSH (in doses 25 and $50 \mathrm{mIU} / \mathrm{mL}$ and 50 and $100 \mathrm{mIU} / \mathrm{mL}$ ) were lower (not significant) than OV-90 cells treated with $100 \mathrm{mIU} / \mathrm{mL}$ FSH alone.

2.6. Cells Overexpressing Wildtype and Mutant piRNA Pathway Genes Have Altered Motility and Invasion In Vitro

In several cancer models, knockdown of piRNA pathway genes result in decreased motility and invasion [56-58]. Initial work in ovarian cancer indicated an opposite trend where overexpression induced decreased motility and invasion [25]. Here, we assessed the effects of overexpression of PIWIL1, PIWIL2 and MAEL as well as known mutants of PIWIL1 (P1 117) and PIWIL2 (PL2L60) on motility and invasion in vitro. Overexpression of PIWIL1, PIWIL2 and PL2L60 in OVCAR-3 had significantly decreased motility compared to the empty vector control (Figure 6a). In OV-90, overexpression of the same set of genes showed decreased motility, however, only PIWIL2 overexpression significantly reduced motility compared to the control (Figure 6b). P1 117 overexpression in OVCAR-3 resulted in a more motile phenotype (nonsignificant) while in OV-90 there was no change in cell motility as compared to their respective empty vector control (Figure 6a,b). Comparing the overexpression of wildtype and mutant PIWIL1 and PIWIL2 motility in both cell lines, only cells overexpressing P1 17 were significantly more motile than PIWIL1 in OVCAR-3 
(Figure 6a). MAEL overexpressing OVCAR-3 and OV-90 cells displayed decreased cell motility (nonsignificant) compared to the empty vector control.
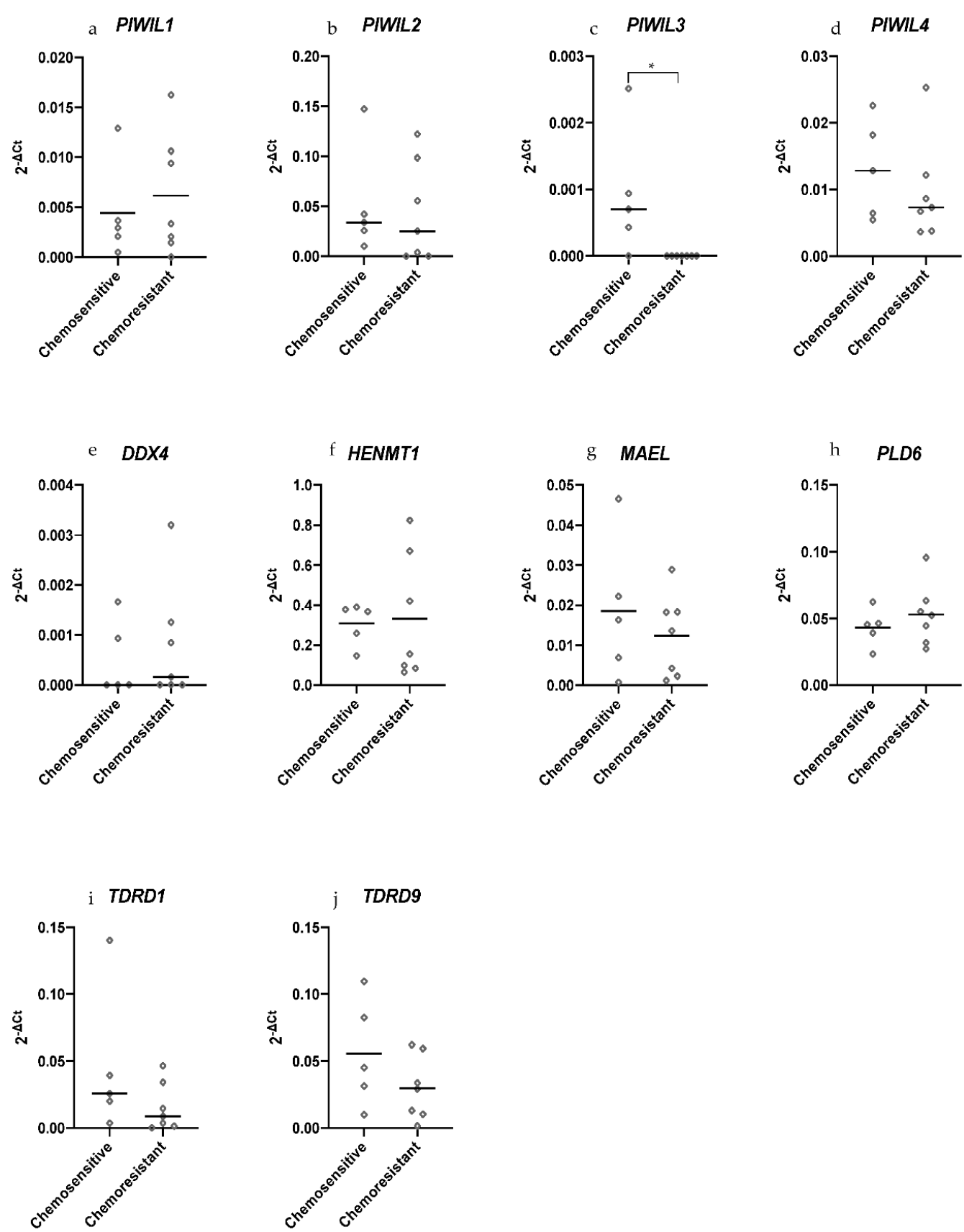

Figure 4. piRNA pathway gene expression in chemosensitive $(n=5)$ and chemoresistant $(n=7)$ primary HGSOC cells. (c) PIWIL3 was not expressed in chemoresistant cells but was expressed in most of the chemosensitive cells $(n=4) .(\mathbf{a}, \mathbf{b}, \mathbf{d}-\mathbf{j})$ While the other genes had no significant change in expression, it was observed that they had varying degrees of differential expression. All Ct scores were normalized to the geomean of housekeepers, TBP and GUSB. Either a median (non-normal distribution) or mean (normal distribution) line was plotted. Statistical tests Mann-Whitney U (non-normal distribution) or unpaired $t$-test (normal distribution) were used accordingly. ${ }^{*} p<0.05$. 
a

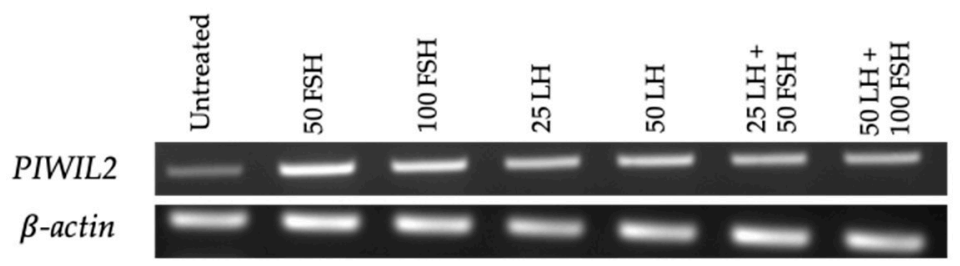

b

PIWIL2

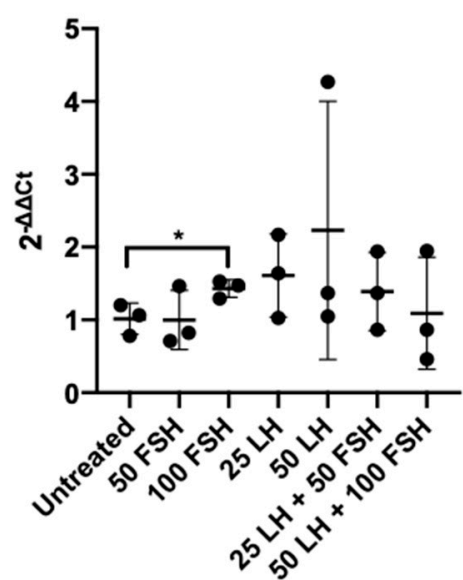

Figure 5. PIWIL2 expression in OV-90 cells before and after a 24-h follicle stimulating hormone (FSH) and luteinizing hormone (LH) treatment. (a) RT-PCR: PIWIL2 expression increased upon individual and combination treatment of FSH and LH. (b) qRT-PCR: PIWIL2 had a significant increase in expression after $100 \mathrm{mIU} / \mathrm{mL}$ FSH treatment. Ct scores were normalized to housekeeper, HPRT1 and the average of untreated cells for $2^{-\triangle \Delta C T}$. Each colored circle represents one biological replicate with technical duplicate where three biological replicates were carried out per treatment group. Labels with numerical values indicate concentration $(\mathrm{mIU} / \mathrm{mL})$ of hormone used. Mean with standard deviation was plotted. Unpaired $t$-test was used to assess significance. ${ }^{*} p<0.05$.

\subsection{OV-90 Cells Overexpressing Mutant PIWIL1 Are More Invasive than Wildtype In Vivo}

The functional roles of PIWIL1, PIWIL2, MAEL, P1 17 and PL2L60 were further assessed in vivo using the chicken chorioallantoic membrane (CAM) invasion assay. We quantified the number of OV-90 cells that successfully invaded into the ectoderm and beyond as a measure of invasion (Figure $7 \mathrm{a}-\mathrm{f}$ ). We found that $P 1 \Delta 17$ overexpressing OV-90 resulted in a significantly more invasive phenotype as compared to the empty vector control and PIWIL1 (Figure 7g). PL2L60, on the other hand, was more invasive than the empty vector control but not significantly more invasive than PIWIL2 (Figure 7g). OV-90 cells overexpressing PIWIL1, PIWIL2 and MAEL showed a slightly more invasive phenotype (nonsignificant) compared to empty vector in vivo (Figure $7 \mathrm{~g}$ ).

Furthermore, OVCAR-3 cells overexpressing PIWIL1, PIWIL2, PL2L60 and MAEL and OV-90 cells overexpressing PIWIL2 showed significantly decreased invasion compared to their respective empty vector control (Figure 6c,d). OVCAR-3 cells overexpressing P1 $\Delta 17$ had increased invasion (nonsignificant) compared to the empty vector control (Figure 6c). Comparison of OVCAR-3 overexpressing wildtype and mutant PIWIL1 demonstrated that this mutant was more invasive (nonsignificant) (Figure 6c). OV-90 cells overexpressing PIWIL1, P1 17 , PL2L60 and MAEL were not significantly different in invasiveness compared to empty vector (Figure $6 \mathrm{~d}$ ). While there was no significant difference in invasion between PIWIL1 and P1 17 overexpression in OV-90 cells, overexpression of PL2L60 was significantly more invasive than PIWIL2 (Figure 6d). 


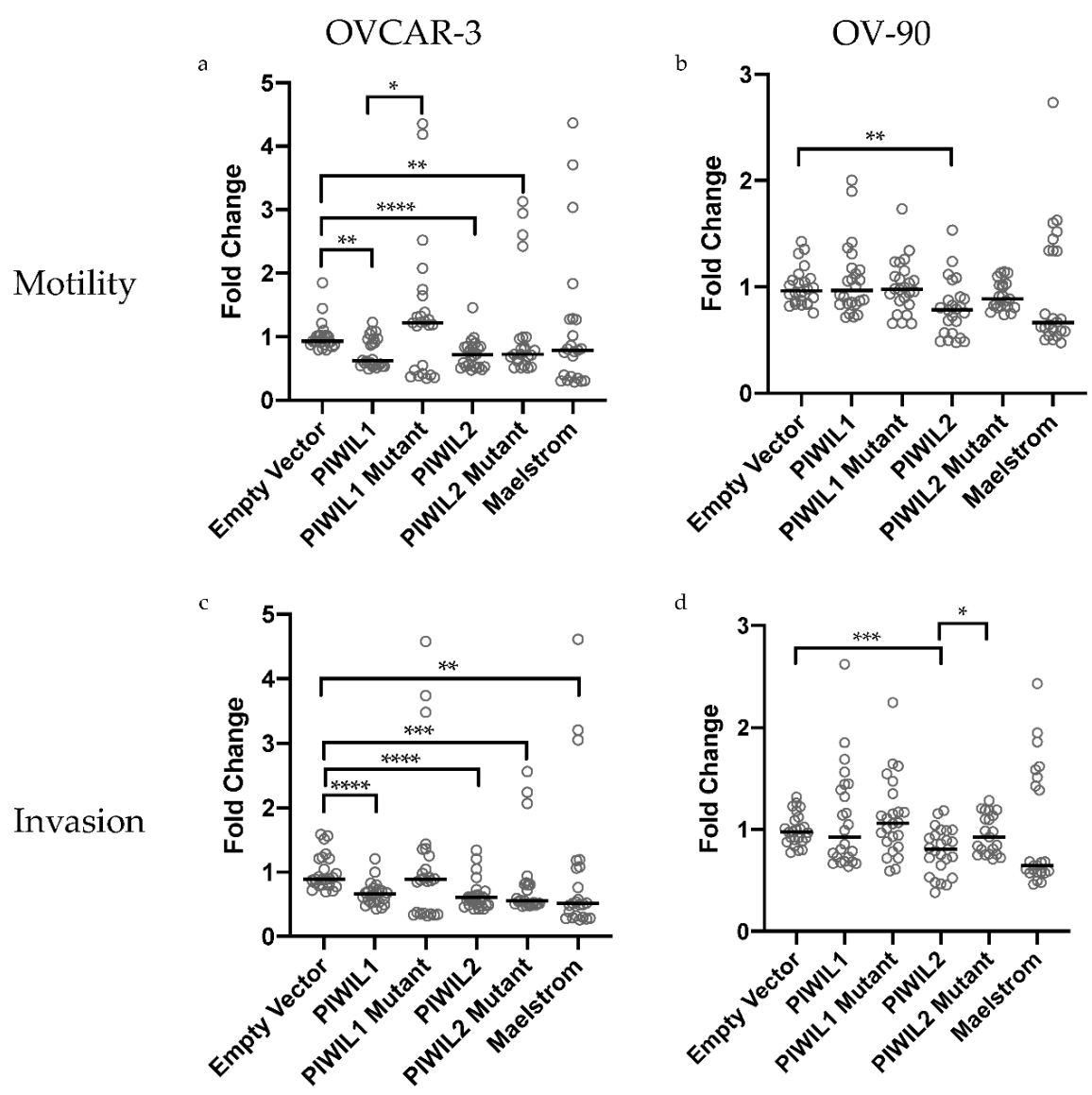

Figure 6. In vitro motility and invasion of OVCAR-3 and OV-90 cells after overexpressing piRNA pathway genes and its mutants ( $n=21-24$ per cell line per transfection). (a,b) Motility: PIWIL1 and PL2L60 (PIWIL2 mutant) overexpression significantly decreased OVCAR-3 motility while PIWIL2 overexpression significantly decreased motility in both OVCAR-3 and OV-90. OVCAR-3 cells overexpressing P1 17 (PIWIL1 mutant) had increased motility compared to empty vector and was significantly more motile than PIWIL1 overexpression. (c,d) Invasion: overexpression of PIWIL1, PIWIL2, PL2L60 and MAEL significantly decreased OVCAR-3 invasion while PIWIL2 overexpression significantly decreased OV-90 invasion. OV-90 cells overexpressing PL2L60 had significantly increased invasion compared to PIWIL2 overexpression. All fold changes were calculated relative to empty vector. Three biological replicates were carried out per cell line per transfection group. Bar represents median values plotted for all the datasets. Statistical tests Mann-Whitney U (non-normal distribution) or unpaired $t$-test (normal distribution) were used accordingly. ${ }^{*} p<0.05 ;{ }^{* *} p<0.005 ;{ }^{* * *} p<0.0005 ;{ }^{* * * *} p<0.0001$. 
a. Empty Vector

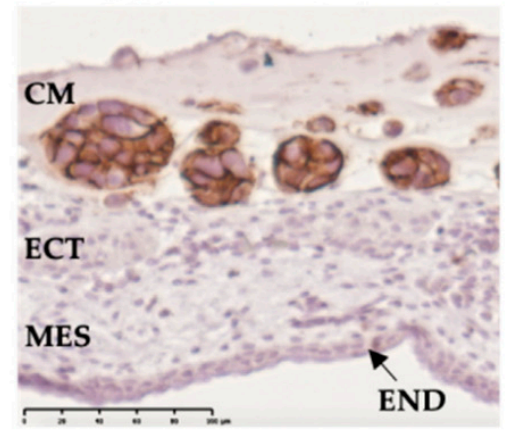

d. PIWIL2

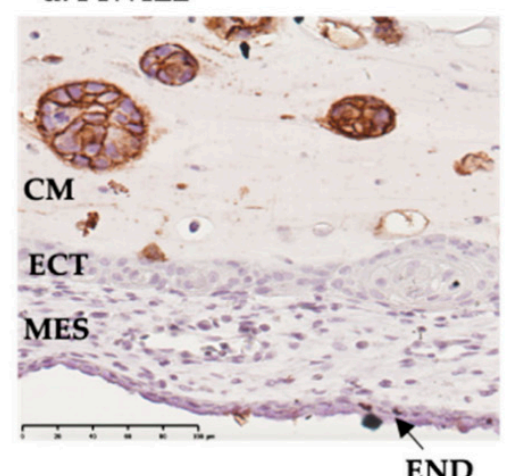

b. PIWIL1

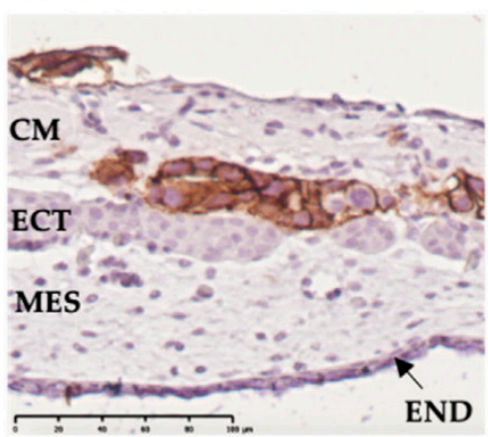

e. PIWIL2 mutant (PL2L60)

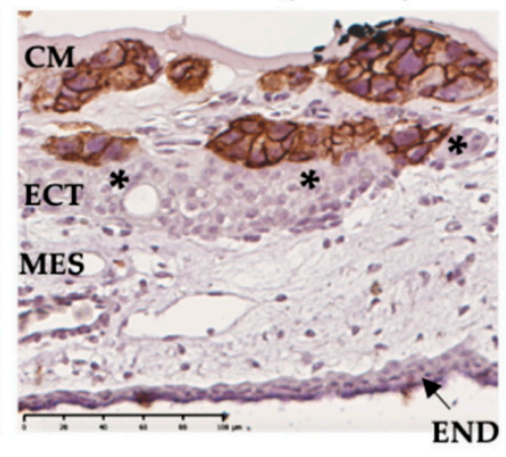

c. PIWIL1 mutant (P1 117$)$

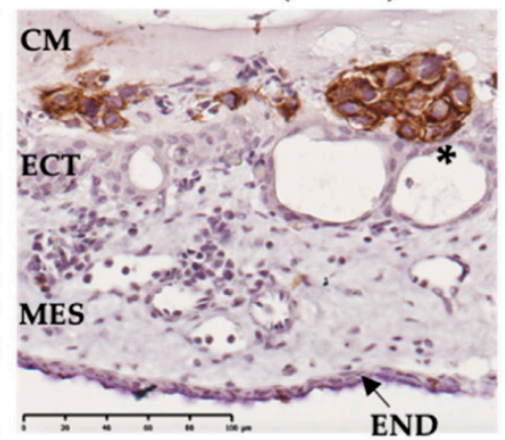

f. $M A E L$

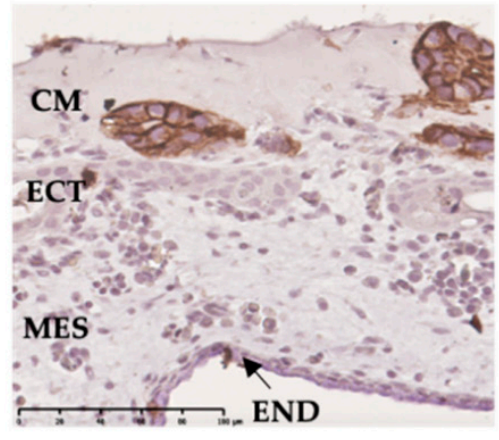

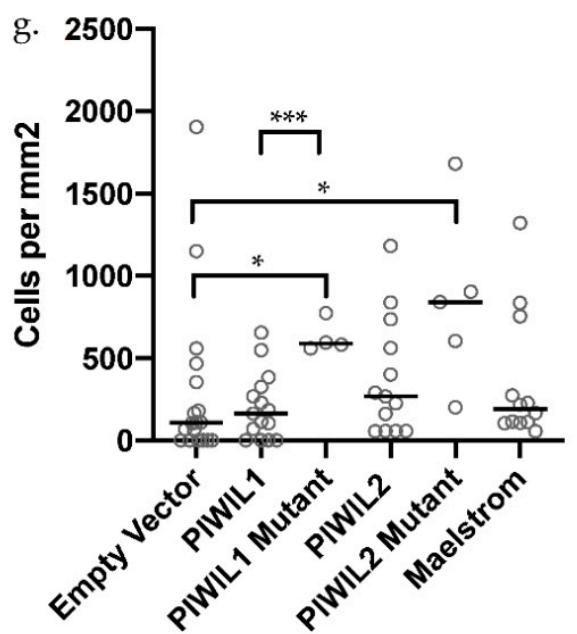

Figure 7. The in vivo invasion analysis using the chicken chorioallantoic membrane (CAM) assay. (a-f) CD44 stained OV-90 cells transfected with (a) empty vector (pcDNA3.1(+)) and overexpression constructs, (b) PIWIL1, (c) P1D17, (d) PIWIL2, (e) PL2L60 and (f) MAEL. CAMs were counterstained with haematoxylin. Invasion was quantified by the number of OV-90 cells that successfully breached the ECT and beyond ( ${ }^{*}$ marked next to breached area). CM = cancer cells mixed with matrigel, ECT $=$ ectoderm, MES = mesoderm, END = endoderm. Scale bar $=100 \mu \mathrm{m}$. (g) Significantly more CAM area was invaded by $P 1 \triangle 17$ and PL2L60 overexpressing OV-90 cells. Both mutants were more invasive than its respective wildtype form where only overexpression of $P 1 \Delta 17$ was significant. $n=4-18$ per construct transfected and carried out in biological duplicates. Statistical tests Mann-Whitney U (non-normal distribution) or unpaired $t$-test (normal distribution) were used accordingly. ${ }^{*} p<0.05 ;{ }^{* * *} p<0.0005$.

\section{Discussion}

The piRNA pathway is increasingly recognized as an important aspect of cancer development and progression [42,43]. Given the limited information of this pathway in OC, we investigated its expression and effects on OC progression. Expression analysis of 
10 selected piRNA pathway genes revealed dynamic changes in relation to OC malignancy, patient survival, and chemoresistance. Additional experiments revealed that FSH treatment on HGSOC cells increased PIWIL2 expression. Furthermore, overexpression studies on the motility and invasion of HGSOC cells demonstrated that PIWIL1 or PIWIL2 mutants can induce a more aggressive phenotype as compared to wildtype in vitro and in vivo.

A number of studies reported that increased expression of piRNA pathway genes contributed to the metastatic progression of various cancers, including OC [56,59-62]. Limited information is available on OC and while knockdown of pathway genes has been linked to decreased malignancy in vitro, overexpression analysis in OC surprisingly revealed decreased invasion [25,56-58]. Our comprehensive analysis revealed a more differentiated pattern where PIWIL1, MAEL and HENMT1 had increased expression, while PIWIL2, PIWIL4 and TDRD1 had decreased expression when comparing benign and malignant tumor samples. This indicates that different aspects of the pathway may be turned up or down as the cancer progresses. For example, PIWIL1 is known to be involved in the primary piRNA biogenesis pathway while PIWIL2 and PIWIL4 participate in the secondary biogenesis pathway. MAEL, HENMT1 and TDRD1 function in both pathways [28,30]. This may be showing that the secondary piRNA biogenesis pathway is specifically downregulated in HGSOC. This also suggests that the pathway genes, having functions beyond piRNA biogenesis, may be behaving independently in malignant tumors. Another possibility is that HGSOC tumors which harbor a high percentage of TP53 mutations and are very genetically unstable may contribute to why our results contrast other cancers $[4-6,11,16]$. Downregulation of piRNA pathway genes in cancer may be uncommon but have been reported in testicular germ cell tumor (PIWIL1, PIWIL2, PIWIL4 and DDX4) and renal cell carcinoma (PIWIL1, PIWIL2 and PIWIL4) and now, also in our expression study for PIWIL2, PIWIL4 and TDRD1 [63,64]. Further evidence that the role of this pathway is more complicated comes from piRNAs where the same piRNA species (piRNA-823) can have a suppressive effect in gastric cancer while oncogenic in multiple myeloma $[65,66]$. Similarly, within gastric cancer, it was observed that different piRNA species can react to support (piRNA-651) and inhibit (piRNA-823) cancer cell growth $[65,67]$. The rapidly increasing body of work highlights the importance of ncRNAs in terms of oncogenicity or tumor suppression in various cancers including OC. For example, different species of microRNAs (miRNAs) can also have oncogenic or tumor suppressive roles in OC [68]. This can be linked to the piRNA pathway and miRNAs regulating transcription factors ZEB1,2 and SNAI1-3 which affect cell epithelial to mesenchymal transition (EMT), enabling the promotion or repression of cell invasion and metastasis $[47,68,69]$. Such piRNA and miRNA species involved in the molecular regulation of cancer progression could be potential targets for OC treatment. Hence, if piRNAs, as part of the piRNA pathway, could function to promote and suppress cancer, it is possible that the pathway genes act in a similar fashion. Together, our findings add to the mounting evidence that the piRNA pathway can act in different ways in different cancers or even different diseases of the same cancer as we demonstrated in OC.

It is accepted that low grade and high grade OC are considered different diseases. Interestingly, this is also reflected in the piRNA pathway expression profile demonstrated by the significantly lower expression of PIWIL1, PIWIL3, PLD6 and TDRD1 in high grade as compared to low grade. HENMT1, on the other hand, had elevated expression in high grade compared to low grade OC. The molecular action for PIWIL3 and PLD6 in low grade OC could be involvement in growth regulation such as in glioma and mediating downstream pathways for proto-oncogene, MYC, as seen in breast cancer, respectively [70,71]. At present, there are no studies of TDRD1 in OC however, TDRD1 is now considered a potential biomarker for prostate cancer as it strongly associates with expression of the frequently mutated transcription factor, ERG [23,49]. Thus, TDRD1 may also be a biomarker for low grade OC. Implications of aberrant HENMT1 expression in cancer are unknown but it has known roles in maintaining piRNA stability by 2'-O-methylation of piRNAs and ensuring TE repression [39,72]. This analysis suggests that piRNA pathway genes may 
have expression profiles specific to the histotype of OC. Interestingly, a microarray study demonstrated similar OC histotype-specific miRNA signatures, supporting the diversity of ncRNA expression in different OC histotypes and highlighting the need for further studies [73].

Next, we assessed whether piRNA pathway gene expression levels were associated with HGSOC progression and patient survival using the KM plotter. High PIWIL1 expression was linked to better PPFS and OS. In contrast, patients with low PIWIL2 and PIWIL4 expression had better PFS. With limited patient data in our gene expression study, we were unable to compare if the lower expressing PIWIL2 and PIWIL4 samples remained progression free as seen using the $\mathrm{KM}$ online plotter. However, the difference in expression level for PIWIL1 versus PIWIL2 and PIWIL4 contributing to better patient outcome was expected given the difference we observed when comparing their expression in benign and malignant tumors as well as low grade OC versus high grade OC. This supports the possibility that the PIWIL genes could be behaving differently in HGSOC. DDX4 and MAEL had conflicting results as they both had low and high expression significantly linked to better prognosis of PFS and OS. The current literature on DDX4 suggests that it plays a role in OC progression due to its influence on DNA damage checkpoints and association with cancer stem cell marker, CD133 [59,60]. Our results showed higher MAEL expression with increasing tumor stage. The association of low MAEL expression with longer PFS in early and late stage HGSOC patients may be related to its putative role in other cancers of promoting EMT and preventing apoptosis and DNA damage in cancer cells [22,47]. However, we observed that high MAEL expression was associated with increased OS in late stage HGSOC. This is consistent with our previous and current work where MAEL overexpression in EOC decreased invasion [25]. High TDRD1 expression was strongly correlated with better PFS but it is currently unknown what its functional role is in cancer other than strong association with ERG expression in prostate cancer [49,74]. On the other hand, low TDRD9 expression was associated with longer PFS. This is consistent with a study where TDRD9 knockdown impaired proliferation of two lung cancer cell lines [61].

The prevalence of chemoresistance in OC and late diagnosis have contributed to its concerningly low 5-year survival rates (26-42\%) and label as one of the most lethal gynecologic malignancies [2]. The mechanisms leading to the development of resistance has yet to be elucidated. Here, we discovered that PIWIL3 was not expressed in chemoresistant HGSOC cells but, interestingly, was expressed in chemosensitive cells. This finding agrees with previous work demonstrating lower PIWIL3 expression in benign and malignant EOC as compared to in a normal ovary which points towards reduced PIWIL3 expression possibly being involved in the progression of OC [25]. In contrast, PIWIL3 had increased expression in more malignant tumors of gastric cancer and melanoma wherein overexpression leads to proliferation and invasion [56,75]. Further conflicting results showed PIWIL3 overexpression induced glioma regression whereas knockdown of PIWIL3 in pancreatic cancer conferred sensitivity to resistant cells [70,76]. Here, we reason that PIWIL3 may be silenced in HGSOC cells as it may play a role in genomic stability through its putative role in piRNA biogenesis [77]. Extensive genomic instability can confer sensitivity to chemotherapy $[78,79]$. Additional work will be needed to address its role in sensitizing HGSOC cells and the mechanism of action in the piRNA pathway. Keeping in mind that our sample size was small, it may be worthwhile exploring PIWIL4, MAEL, PLD6, TDRD1 and TDRD9 as potential targets in addition to PIWIL3 for overcoming chemotherapy resistance.

The effects of hormones on the piRNA pathway have been reported in mice, frogs and fish with only one study in breast and prostate cancer [80-84]. Exploring this novel avenue in OC, we exposed a HGSOC cell line, OV-90, with varying concentrations of FSH and LH. We found that a higher concentration of FSH was able to stimulate increased PIWIL2 expression but none of the treatments stimulated a change in PIWIL1 or MAEL expression [85] PIWIL2 had no change in expression when treated with a high dose of combined FSH and LH. This could be explained by their antagonistic nature where FSH induced cell proliferation was blocked when LH was introduced in EOC cell lines [86]. 
We postulate that PIWIL2 may be a downstream target of FSH as they both affect proteins involved in cell proliferation and EMT pathways namely, STAT3 and MMP-9 [57,87,88]. Another set of proteins that PIWIL2 and FSH are involved in regulating are stem cell markers, OCT4, NANOG and SOX-2 [89-91]. In addition, induction of PIWIL2 was also reported to endow cancer stem cell-like properties to human fibroblasts with ectopic expression of these stemness markers [90]. While there are many papers on FSH causing OC proliferation and migration [4,92-95], there is a study claiming FSH as having protective properties against cancer [96]. Therefore, further investigation is needed to identify the relationship between FSH and PIWIL2 and whether they contribute to or against the development of HGSOC.

To establish the effects of increased piRNA pathway gene expression on HGSOC motility and invasion in vitro and in vivo, we assessed this in 2 HGSOC cell lines, OVCAR3 and OV-90, both harboring a TP53 missense mutation [97]. Our previous work on SKOV-3 overexpressing PIWIL1 and MAEL showed a decrease in invasion in vitro [25]. Here, we expanded the overexpression study to include PIWIL2, P1 17 and PL2L60 in cell lines, OVCAR-3 and OV-90. As well as demonstrating similar results for PIWIL1 and MAEL as SKOV-3 cells, we revealed that OVCAR-3 and OV-90 cells overexpressing PIWIL2, P1 17 and PL2L60 also had decreased motility and invasion compared to empty vector transfected cells. This is unexpected as in most cancers, the overexpression of these wildtype and mutant piRNA pathway genes were associated with a more invasive phenotype [50,98-100]. Key cancer-related pathways and proteins that these genes can regulate include the AKT/GSK-3 $\beta$ /SNAIL pathway, MMP-9, CD44 and STMN1 which are involved in EMT and metastasis $[47,57,88,89,99]$. There is a possibility that these pathways and proteins react differently in HGSOC due to genomic instability and the presence of TP53 mutants that could either have loss-of-function, gain-of-function or dominant negative mutations [16]. More importantly, TP53 mutants are more resistant to degradation than the wildtype form, hence could cause different outcomes regardless of the presence of wildtype TP53 [16]. There is evidence that PIWIL2 can form a complex with STAT3 and c-SRC through interaction with its PAZ domain to repress TP53 transcription [101,102]. Could PIWIL2 have a protective role by downregulating mutant TP53 in HGSOC? It is interesting that OVCAR-3 and OV-90 cells overexpressing P1 17 and PL2L60 were more invasive as compared to cells overexpressing PIWIL1 and PIWIL2. This may be attributed to the truncation of their PIWI and PAZ domains, respectively [25,50]. It is possible that truncation of these domains could lead to impaired piRNA binding, endonuclease activity and interaction with the growing list of oncogenes and tumor suppressors.

\section{Materials and Methods}

\subsection{Patient Cohort}

Patient tissue samples were obtained with written consent and approval by the Central Adelaide Local Health Network Human Research Ethics Committee (RAH Protocol \#140201). Clinicopathological characteristics of the patient samples used in the Fluidigm qRT-PCR expression analysis are listed in Tables S1 and S2. Ethics Committee approval was obtained on 13 January 2014. Formalin-fixed paraffin-embedded (FFPE) tissue sections of patients were stained with hematoxylin and eosin to confirm cancer content [85] RNA extractions were then carried out on frozen patient tissues which FFPE sections had at least $50 \%$ cancer content.

\subsection{RNA Extraction, $c D N A$ Synthesis and Quantification}

RNA extractions and cDNA syntheses were carried out on all samples using TRIzol (Thermo Fisher Scientific, Waltham, MA, USA) and iScript cDNA synthesis kit (Bio-Rad Laboratories, Hercules, CA, USA) according to the manufacturers' protocol. RNA samples were quantified using Qubit (Invitrogen, Waltham, MA, USA) where 400 ng was cDNA synthesized and $2 \mu \mathrm{L}$ of cDNA was used in the Fluidigm high throughput qRT-PCR. For the RT-PCRs and other qRT-PCRs, RNA samples were quantified using NanoDrop (Thermo 
Fisher Scientific, Waltham, MA, USA). A $1 \mu \mathrm{g}$ sample of RNA was used for each cDNA synthesis reaction and diluted 1 in 5 after the reaction. A sample of $5 \mu \mathrm{L}$ was then used in the RT-PCRs and $2 \mu \mathrm{L}$ in the other qRT-PCRs.

\subsection{Primary and Established Ovarian Cancer Cell Lines}

Chemosensitive $(n=5)$ and chemoresistant $(n=7)$ primary cells were obtained from ascites of high grade OC patients before and after chemotherapy treatment as previously described [103]. Chemoresistance was determined when patients relapse and no longer respond to chemotherapy. Chemosensitivity was classified as patients responding to chemotherapy and not progressing within 6 months of completing their treatment. These primary cells were grown in Advanced RPMI 1640 media (Gibco, Waltham, MA, USA, cat no. 12633-020) containing 10\% fetal calf serum (FCS) (Scientifix, Clayton, VIC, Australia) and 1\% each of penicillin/streptomycin (Life Technologies, Mulgrave, VIC, Australia), fungizone (Sigma-Aldrich, St. Louis, MO, USA) and glutamax (Life Technologies, Mulgrave, VIC, Australia) and maintained at $37^{\circ} \mathrm{C}$ in a $6 \% \mathrm{CO}_{2}$ environment.

Human HGSOC cell lines, OVCAR-3 and OV-90, were purchased from the American Type Culture Collection (ATCC, Manassas, VA, USA). They were cultured in RPMI 1640 (Gibco, Waltham, MA, USA, cat no. 11875-093) with FCS (5\% for OVCAR-3, 10\% for OV-90), $1 \%$ penicillin/streptomycin and $1 \%$ glutamax.

\subsection{Quantitative Real-Time PCR (qRT-PCR)}

To assess piRNA pathway gene expression in HGSOC tumors, chemosensitive and chemoresistant primary HGSOC cells, a high throughput gene expression qRT-PCR (Fluidigm, South San Francisco, CA, USA) was performed at the Australian Cancer Research Foundation Cancer Genomics Facility using the 96.96 Dynamic Array integrated fluidic circuit (IFC) (Integrated Sciences, Chatswood, NSW, Australia). The 20X Taqman assays (listed in Table S3), $2 \mu \mathrm{L}$ each, were pooled and cDNA preamplified under cycling conditions: $95^{\circ} \mathrm{C}$ for $2 \mathrm{~min}$ then 14 cycles of $95^{\circ} \mathrm{C}$ for $15 \mathrm{~s}$ lastly, $60^{\circ} \mathrm{C}$ for $4 \mathrm{~min}$ on the $\mathrm{C} 1000$ cycler (Bio-Rad Laboratories, Hercules, CA, USA). IFC Controller MX (Fluidigm, South San Francisco, CA, USA) was used to prime the IFC with control line fluid (Fluidigm, South San Francisco, CA, USA) using the Prime $(136 \times)$ script. Load Mix $(136 \times)$ script was utilized to load samples and assays. A premix containing preamplified cDNA, 2X Quanta PerfeCTa qPCR Fast Mix, low ROX (Quanta BioSciences, Beverly, MA, USA) and 20X GE Sample Loading Reagent (Fluidigm, South San Francisco, CA, USA) was made. The premix and Taqman assays with 2 X Assay Loading Reagent (Fluidigm, South San Francisco, CA, USA) were loaded into individual inlets. Thermal cycling then started in the BioMark HD System (Fluidigm, South San Francisco, CA, USA) with $45{ }^{\circ} \mathrm{C}$ for $2 \mathrm{~min}$, thermal mix: $70{ }^{\circ} \mathrm{C}$ for $40 \mathrm{~min}$ and $60^{\circ} \mathrm{C}$ for $30 \mathrm{~s}$, hot start: $98^{\circ} \mathrm{C}$ for $1 \mathrm{~min}$, followed by 35 cycles of $97{ }^{\circ} \mathrm{C}$ for $5 \mathrm{~s}$ and lastly, $60^{\circ} \mathrm{C}$ for $20 \mathrm{~s}$. Gene expression data was collected using the BioMark HD Data Collection software (Fluidigm, South San Francisco, CA, USA). Visualization and exportation of data were performed using the Fluidigm Real-Time PCR Analysis software (Fluidigm, South San Francisco, CA, USA). The $2^{-\Delta \mathrm{CT}}$ method was used to normalize the $\mathrm{Ct}$ values to the geomean of the Ct of housekeepers, TBP and GUSB.

To confirm PIWIL2 expression after hormone treatment on OV-90 cells, qRT-PCR was carried out using Taqman assays HPRT1 and PIWIL2 (Table S3). Technical duplicates of Taqman gene expression master mix, respective Taqman assays and cDNA were loaded in the MicroAmp Fast Optical 96-well plate (Applied Biosystems, Waltham, MA, USA) for thermal cycling in the StepOnePlus System (Applied Biosystems, Waltham, MA, USA). Cycling conditions were: $50^{\circ} \mathrm{C}$ for $2 \mathrm{~min}, 95^{\circ} \mathrm{C}$ for $10 \mathrm{~min}, 40$ cycles of $95^{\circ} \mathrm{C}$ for $15 \mathrm{~s}$ and $60{ }^{\circ} \mathrm{C}$ for $1 \mathrm{~min}$. The $2^{-\Delta \Delta \mathrm{CT}}$ method was used to normalize PIWIL2 Ct values to housekeeper, HPRT1.

GraphPad Prism 8 was used for all statistical analysis. Normality of data was tested using the Shapiro-Wilk test followed by either Kruskal-Wallis (non-normal distribution) or one-way ANOVA (normal distribution) for comparing expression in benign, early and 
late stage HGSOC samples and Mann-Whitney U (non-normal distribution) or unpaired $t$-test (normal distribution) for comparing expression of chemosenstive and chemoresistant primary cells in the Fluidigm qRT-PCR. Mann-Whitney U test (non-normal distribution) was used to analyze the expression differences between benign and cancerous samples. Data from the other qRT-PCRs were subjected to the Shapiro-Wilk test followed by unpaired $t$-test as the data was normally distributed.

\subsection{Public Microarray Online Databases}

Expression profiles of the piRNA pathway genes across OC grades 1-3 were evaluated using CSIOVDB (http: / / csiovdb.mc.ntu.edu.tw /CSIOVDB.html), a microarray gene expression database $n=3431$ [104]. The OC subtypes analyzed consisted of clear cell, endometrioid, mucinous, and serous. The Kaplan-Meier plotter (http:/ kmplot.com/ analysis /) was used to examine the relationship with PFS, PPFS and OS for OC $(n=2190)$ patients and expression levels of the piRNA pathway genes (Table S4) [105]. There was no microarray data available for PIWIL3. Parameters were set in accordance with the Fluidigm samples of HGSOC (grades 2 and 3). Early stage consisted of stage 1 and 2 while the late stage consisted of only stage 3 HGSOC patients. Patients were split by the best cut-off selected by the online plotter tool.

\subsection{Overexpression Transfections}

Transfections on OVCAR-3 and OV-90 were carried out using Attractene (Qiagen, Chadstone, VIC, Australia) according to the manufacturer's protocol. To ensure better survival and transfection efficiency, the cells were seeded $48 \mathrm{~h}$ pre-transfection at $40-50 \%$ confluency and the culture media was replaced with Opti-MEM (Gibco, Waltham, MA, USA, cat no. 11835-030) for DNA and Attractene complex formation. The passage number was kept below 10 post-thaw for all transfections to reduce variability in experiments. Cells were harvested 60-65 h post transfection for subsequent assays. pcDNA3.1 (+) plasmid (Invitrogen, Waltham, MA, USA) was used as the empty vector control. Overexpression constructs were PIWIL1 (oHu24048), PIWIL2 (oHu26193) and MAEL (oHu11219) inserted in pcDNA3.1 (+) plasmids (GenScript, Piscataway, New Jersey, USA), respectively. Overexpression mutant constructs, P1 17 and PL2L60 (GenScript, Piscataway, New Jersey, USA), were made by removing exon 17 from PIWIL1 cDNA (ENST00000245255.7) and a readily available PL2L60 cDNA sequence (AK027497.1) inserted in pcDNA3.1 (+) plasmids.

\subsection{RT-PCR}

RT-PCRs were performed on a $94{ }^{\circ} \mathrm{C}$ preheated C1000 Touch thermal cycler (Bio-Rad Laboratories, Hercules, CA, USA) with cycling conditions: $94{ }^{\circ} \mathrm{C}$ for $30 \mathrm{~s}, 35$ cycles of $94{ }^{\circ} \mathrm{C}$ for $30 \mathrm{~s}, 55^{\circ} \mathrm{C}\left(\beta\right.$-actin) $/ 59^{\circ} \mathrm{C}$ (PIWIL2) for $30 \mathrm{~s}, 68^{\circ} \mathrm{C}$ for $1 \mathrm{~min}$ followed by a final extension of $68^{\circ} \mathrm{C}$ for $5 \mathrm{~min}$. The composition of each $25 \mu \mathrm{L}$ reaction using OneTaq DNA polymerase (New England Biolabs, Ipswich, MA, USA) were following manufacturer's protocol. The ChemiDoc MP Imager (Bio-Rad Laboratories, Hercules, CA, USA) was used to visualize PCR products on $2 \%$ agarose gels stained with ethidium bromide and generate images. $\beta$-actin and PIWIL2 primers (Table S5) were purchased from Integrated DNA Technologies.

\subsection{In Vitro Motility and Invasion Assay}

The ChemoTx ${ }^{\circledR}$ 96-well plate (Neuroprobe, Gaithersburg, MD, USA) was used to assess motility of transfected OVCAR-3 and OV-90 cells. Addition of an even spread of dried 0.6 $\mu$ L Geltrex (Gibco, Waltham, MA, USA) diluted 1:1 with media (RPMI1640 + 0.1\% BSA) on the filter membrane was used to determine invasion. Briefly, cells were labelled with calcein AM (Life Technologies, Mulgrave, VIC, Australia) after 30 min of incubation in the dark on a nutator. Excess calcein AM were removed by washing the cells twice with media (RPMI1640 + 0.1\% BSA). Portions of $4 \times 10^{4}$ cells were then pipetted onto each pore of the filter above a microplate containing wells prefilled with chemoattractant (10\% FCS) 
and media (RPMI1640 + 0.1\% BSA). Reverse pipetting was employed at every step to prevent bubble entrapment. After a 6-hour, $37^{\circ} \mathrm{C}$ incubation, cells that had migrated or invaded the filter were measured using the Triad series multimode detector (Dynex Technologies, Chantilly, VA, USA) at 485-520 nm. Assays were carried out in biological triplicate and had technical replicates to a total of $n=21-24$ per cell line per construct transfected. Statistical analysis was carried out on GraphPad Prism 8 first by Shapiro-Wilk test of normality followed by either Mann-Whitney $U$ test (non-normal distribution) or unpaired $t$-test (normal distribution).

\subsection{Chicken Chorioallantoic Membrane (CAM) Assay and Immunohistochemistry}

The CAM assays for OV-90 cells were carried out as described previously [106]. CAM harvested from each embryo had 1-2 separate onplants consisting of a mixture of 90,000 cells and matrigel ( $n=4-18$ per construct transfected) for analysis. Paraffin serial sections $(5 \mu \mathrm{m})$ were stained with hematoxylin and eosin to determine the best paired section for immunohistochemistry (IHC). Paraffin sections for IHC were firstly placed on a $60{ }^{\circ} \mathrm{C}$ heat plate for a minimum of $1 \mathrm{~h}$ then dewaxed with $100 \%$ xylene and ethanol and washed in 1X PBS. After incubating for $5 \mathrm{~min}$ in $1 \% \mathrm{H}_{2} \mathrm{O}_{2}$ and 1 X PBS washes, citrate buffer antigen retrieval was performed in a steam microwave (Sixth Sense, Whirlpool, Dandenong South, VIC, Australia) for $10 \mathrm{~min}$. Sections were incubated for $30 \mathrm{~min}$ in blocking buffer (5\% goat serum in 1X PBS) before an overnight incubation with 1:800 CD44 antibody (Thermo Fisher Scientific, Waltham, MA, USA, cat no. \#MA5-13890) in blocking buffer. With 1X PBS washes in between, sections underwent an hour incubation of 1:400 goat anti-mouse antibody (Dako, Agilent, Santa Clara, CA, USA, cat no. \#E0433) in blocking buffer, an hour incubation of 1:500 streptavidin (Dako, Agilent, Santa Clara, CA, USA, cat no. \#P0397) in $1 X$ PBS and 6 min of $1: 1 \mathrm{DAB}$ and $\mathrm{H}_{2} \mathrm{O}_{2}$ mixture. Lastly, sections were counterstained with hematoxylin, dipped in 70\% ethanol, 100\% ethanol, 100\% xylene and mounted with Pertex mounting medium (HD Scientific, Ringwood, VIC, Australia). After drying, slides were scanned with the Nanozoomer Digital Pathology System (Hamamatsu Photonics, Hamamatsu City, Shizuoka Prefecture, Japan). The NDP scan software v2.2 (Hamamatsu Photonics, Hamamatsu City, Shizuoka Prefecture, Japan) was used to collect slide images and quantify cells that crossed the ectoderm as a measure of invasion. CAM assays were carried out on biological duplicates. Statistical analysis was carried out on GraphPad Prism 8 first by Shapiro-Wilk test of normality followed by either Mann-Whitney U test (non-normal distribution) or unpaired $t$-test (normal distribution). Ethical approval was obtained on 5 October 2018 from the University of Adelaide Animal Ethics Committee (\#33109).

\subsection{FSH and LH Treatment}

OV-90 cells $\left(1 \times 10^{6}\right)$ were seeded in T25 flasks and cultured for at least $24 \mathrm{~h}$ in normal culture media. Next, the flasks were rinsed with phenol red-free RPMI 1640 (Gibco, Waltham, MA, USA, cat no. 11835-030) and cultured in "complete" media for a minimum of $24 \mathrm{~h}$. "Complete" media consisted of phenol red-free RPMI 1640, 1\% each of AlbuMAX II 20\% solution (Life Technologies, Mulgrave, VIC, Australia, cat no. E003000PJ), SPITE 100X (Sigma-Aldrich, St. Louis, MO, USA, cat no. S5666), penicillin/streptomycin, glutamax and $0.2 \%$ fungizone. Hormone treatment media then replaced the "complete" media for $24 \mathrm{~h}$ before RNA was harvested for subsequent RT-PCR and qRT-PCR. The untreated control was maintained in "complete" media. Hormone treatments were made up in "complete" media: $50 \mathrm{mIU} / \mathrm{mL}$ FSH, $100 \mathrm{mIU} / \mathrm{mL}$ FSH, $25 \mathrm{mIU} / \mathrm{mL} \mathrm{LH,} 50 \mathrm{mIU} / \mathrm{mL}$ LH, $50 \mathrm{mIU} / \mathrm{mL} \mathrm{FSH}+25 \mathrm{mIU} / \mathrm{mL} \mathrm{LH}$ and $100 \mathrm{mIU} / \mathrm{mL}$ FSH + $50 \mathrm{mIU} / \mathrm{mL}$ LH. FSH (AFP7298A) and LH (AFP-4395A) were purchased from the National Hormone and Peptide Program (Torrance, CA, USA). 


\section{Conclusions}

In summary, our extensive analysis of piRNA pathway genes in OC adds to the growing knowledge base about the role of this pathway in cancer. Differential expression of these piRNA pathway genes in OC depicts a more complex association of their expression with various aspects of malignancy, patient survival, chemoresistance, gonadotropin treatment and invasion. The observation that piRNA pathway genes may act differently in the HGSOC context compared to other cancers is possibly due to its exceptionally high proportion of TP53 mutations, genomic instability and highly heterogeneous nature. Here, we present an expression profile of 10 piRNA pathway genes in benign ovarian tumors, low grade OC and HGSOC and their effects on patient survival. We identified PIWIL3 as a potential target for chemoresistance in HGSOC. Further, we made a novel discovery that FSH can mediate PIWIL2 expression. Together with in vitro and in vivo studies, we revealed that overexpression of PIWIL1, P1 17 , PIWIL2, PL2L60 and MAEL caused a decrease in motility and invasion. However, mutants P1 $\triangle 17$ and PL2L60 surprisingly induced a more invasive phenotype compared to wildtype. While providing a deeper understanding, this work also raises a number of questions about the complicated relationship between piRNAs, the pathway genes and their functions in OC pathogenesis. Additional work is required to further explore the clinical relevance of the variability in piRNAs and pathway genes in OC patients.

Supplementary Materials: The following are available online at https://www.mdpi.com/2072 -6694/13/1/4/s1, Table S1: Clinicopathological characteristics of benign and high grade serous ovarian cancer cohort used in the Fluidigm qRT-PCR. Table S2: Clinicopathological characteristics of chemosenstitive and chemoresistant ovarian cancer patient cohort used in the Fluidigm qRT-PCR. Table S3: Taqman assays used in qRT-PCR. Table S4: Affymetrix ID of piRNA pathway genes assessed in the Kaplan-Meier plotter. Table S5: Primers used in RT-PCR.

Author Contributions: Conceptualization, E.L. and F.G.; methodology, E.L. and N.A.L.; software, E.L.; validation, E.L.; formal analysis, E.L., N.A.L. and C.R.; investigation, E.L.; resources, M.K.O.; writing—original draft preparation, E.L.; writing—review and editing, E.L., N.A.L., M.K.O., C.R. and F.G.; visualization, E.L.; supervision, N.A.L., M.K.O., C.R. and F.G. All authors have read and agreed to the published version of the manuscript.

Funding: E.L. is supported by the Adelaide Graduate Research Scholarship. C.R. is supported by the Lin Huddleston Ovarian Cancer Fellowship funded by the Cancer Council South Australia and the Adelaide Medical School, University of Adelaide. F.G. is supported by the Australian Research Council Future Fellowship.

Institutional Review Board Statement: The study was conducted according to the guidelines of the Declaration of Helsinki, and approved by the Ethics Committee of Central Adelaide Local Health Network Human Research (RAH Protocol \#140201, date approved 13 January 2014) and Animal Ethics Committee of the University of Adelaide (\#33109, date approved 5 October 2018).

Informed Consent Statement: Informed consent was obtained from all subjects involved in the study.

Data Availability Statement: The data presented in this study are available in this article and supplementary materials.

Acknowledgments: We thank Anne Macpherson for providing the hormone treatment protocol and advice on analyzing the high throughput qRT-PCR data. We thank Jia Quyen Truong for his help with sorting the raw output of the high throughput qRT-PCR. We also thank Reuben Jacob for his advice on interpreting the piRNA pathway gene expression profile.

Conflicts of Interest: The authors declare no conflict of interest. The funders had no role in the design of the study; in the collection, analyses, or interpretation of data; in the writing of the manuscript, or in the decision to publish the results. 


$\begin{array}{ll}\text { Abbreviations } & \\ \text { BSA } & \text { Bovine serum albumin } \\ \text { CAM } & \text { Chicken chorioallantoic membrane } \\ \text { CSIOVDB } & \text { Ovarian cancer database of Cancer Science Institute Singapore } \\ \text { DAB } & \text { 3:3'-diaminobenzidine } \\ \text { DDX4 } & \text { DEAD-Box Helicase } 4 \\ \text { EMT } & \text { Epithelial to mesenchymal transition } \\ \text { EOC } & \text { Epithelial ovarian cancer } \\ \text { FFPE } & \text { Formalin-fixed paraffin-embedded } \\ \text { FIGO } & \text { Fédération Internationale de Gynécologie et d'Obstétrique } \\ \text { FSH } & \text { Follicle stimulating hormone } \\ \text { GUSB } & \text { Glucuronidase Beta } \\ \text { HGSOC } & \text { High grade serous ovarian cancer } \\ \text { HENMT1 } & \text { HEN Methyltransferase 1 } \\ \text { HR } & \text { Hazard ratio } \\ \text { KM } & \text { Kaplan-Meier } \\ \text { LH } & \text { Luteinizing hormone } \\ \text { MAEL } & \text { Maelstrom } \\ \text { miRNA } & \text { MicroRNA } \\ \text { ncRNA } & \text { Noncoding RNA } \\ \text { OC } & \text { Ovarian cancer } \\ \text { OS } & \text { Overall survival } \\ \text { PBS } & \text { Phosphate-buffered saline } \\ \text { PFS } & \text { Progression free survival } \\ \text { piRNA } & \text { PIWI-interacting RNA } \\ \text { PIWIL (1-4) } & \text { P-element induced wimpy testis-like (1-4) } \\ \text { PLD6 } & \text { Phospholipase D Family Member 6 } \\ \text { PPFS } & \text { Post-progression free survival } \\ \text { SNAI (1-3) } & \text { Snail family zinc finger (1-3) } \\ \text { TBP } & \text { TATA-Box Binding Protein } \\ \text { TDRD (1:9) } & \text { Tudor Domain Containing (1,9) } \\ \text { TE } & \text { Transposable element } \\ \text { ZEB (1,2) } & \text { Zinc finger E-box binding homeobox (1,2) } \\ & \end{array}$

\section{References}

1. Bray, F.; Ferlay, J.; Soerjomataram, I.; Siegel, R.L.; Torre, L.A.; Jemal, A. Global cancer statistics 2018: GLOBOCAN estimates of incidence and mortality worldwide for 36 cancers in 185 countries. CA A Cancer J. Clin. 2018, 68, 394-424. [CrossRef] [PubMed]

2. Torre, L.A.; Trabert, B.; DeSantis, C.E.; Miller, K.D.; Samimi, G.; Runowicz, C.D.; Gaudet, M.M.; Jemal, A.; Siegel, R.L. Ovarian cancer statistics, 2018. CA A Cancer J. Clin. 2018, 68, 284-296. [CrossRef] [PubMed]

3. Kurman, R.J.; Visvanathan, K.; Roden, R.; Wu, T.C.; Shih, I.-M. Early Detection and Treatment of Ovarian Cancer: Shifting from Early Stage to Minimal Volume of Disease Based on a New Model of Carcinogenesis. Am. J. Obstet. Gynecol. 2008, 198, 351-356. [CrossRef]

4. Mertens-Walker, I.; Baxter, R.C.; Marsh, D.J. Gonadotropin signalling in epithelial ovarian cancer. Cancer Lett. 2012, 324, 152159. [CrossRef]

5. Gharwan, H.; Bunch, K.P.; Annunziata, C.M. The role of reproductive hormones in epithelial ovarian carcinogenesis. Endocr. Relat. Cancer 2015, 22, R339-R363. [CrossRef]

6. Kurman, R.J.; Shih, I.-M. The Dualistic Model of Ovarian Carcinogenesis: Revisited, Revised, and Expanded. Am. J. Pathol. 2016, 186, 733-747. [CrossRef] [PubMed]

7. Webb, P.M.; Jordan, S.J. Epidemiology of epithelial ovarian cancer. Best Pract. Res. Clin. Obstet. Gynaecol. 2017, 41, 3-14. [CrossRef] [PubMed]

8. Prat, J. Ovarian carcinomas: Five distinct diseases with different origins, genetic alterations, and clinicopathological features. Virchows Arch. 2012, 460, 237-249. [CrossRef]

9. Boussios, S.; Moschetta, M.; Zarkavelis, G.; Papadaki, A.; Kefas, A.; Tatsi, K. Ovarian sex-cord stromal tumours and small cell tumours: Pathological, genetic and management aspects. Crit. Rev. Oncol. Hematol. 2017, 120, 43-51. [CrossRef]

10. Lheureux, S.; Braunstein, M.; Oza, A.M. Epithelial ovarian cancer: Evolution of management in the era of precision medicine. CA A Cancer J. Clin. 2019, 69, 280-304. [CrossRef]

11. Lisio, M.-A.; Fu, L.; Goyeneche, A.; Gao, Z.-H.; Telleria, C. High-Grade Serous Ovarian Cancer: Basic Sciences, Clinical and Therapeutic Standpoints. Int. J. Mol. Sci. 2019, 20, 952. [CrossRef] [PubMed]

12. Flaum, N.; Crosbie, E.J.; Edmondson, R.J.; Smith, M.J.; Evans, D.G. Epithelial ovarian cancer risk: A review of the current genetic landscape. Clin. Genet. 2020, 97, 54-63. [CrossRef] [PubMed] 
13. Olivier, M.; Hollstein, M.; Hainaut, P. TP53 mutations in human cancers: Origins, consequences, and clinical use. Cold Spring Harb. Perspect. Biol. 2010, 2, a001008. [CrossRef] [PubMed]

14. Vang, R.; Levine, D.A.; Soslow, R.A.; Zaloudek, C.; Shih, I.-M.; Kurman, R.J. Molecular alterations of TP53 are a defining feature of ovarian high-grade serous carcinoma: A rereview of cases lacking TP53 mutations in the Cancer Genome Atlas Ovarian Study. Int. J. Gynecol. Pathol. Off. J. Int. Soc. Gynecol. Pathol. 2016, 35, 48. [CrossRef] [PubMed]

15. Kim, S.; Han, Y.; Kim, S.I.; Kim, H.-S.; Kim, S.J.; Song, Y.S. Tumor evolution and chemoresistance in ovarian cancer. Npj Precis. Oncol. 2018, 2, 1-9. [CrossRef]

16. Zhang, Y.; Cao, L.; Nguyen, D.; Lu, H. TP53 mutations in epithelial ovarian cancer. Transl. Cancer Res. 2016, 5, 650-663. [CrossRef]

17. Telloni, S.M. Tumor Staging and Grading: A Primer. In Molecular Profiling: Methods and Protocols; Espina, V., Ed.; Springer: New York, NY, USA, 2017; pp. 1-17. [CrossRef]

18. Slomovitz, B.; Gourley, C.; Carey, M.S.; Malpica, A.; Shih, I.-M.; Huntsman, D.; Fader, A.N.; Grisham, R.N.; Schlumbrecht, M.; Sun, C.C. Low-grade serous ovarian cancer: State of the science. Gynecol. Oncol. 2020, 156, 715-725. [CrossRef]

19. Hanahan, D.; Weinberg, R.A. Hallmarks of Cancer: The Next Generation. Cell 2011, 144, 646-674. [CrossRef]

20. Shibue, T.; Weinberg, R.A. EMT, CSCs, and drug resistance: The mechanistic link and clinical implications. Nat. Rev. Clin. Oncol. 2017, 14, 611. [CrossRef]

21. Han, Y.N.; Li, Y.; Xia, S.Q.; Zhang, Y.Y.; Zheng, J.H.; Li, W. PIWI Proteins and PIWI-Interacting RNA: Emerging Roles in Cancer. Cell. Physiol. Biochem. 2017, 44, 1-20. [CrossRef]

22. Kim, S.-H.; Park, E.-R.; Cho, E.; Jung, W.-H.; Jeon, J.-Y.; Joo, H.-Y.; Lee, K.-H.; Shin, H.-J. Mael is essential for cancer cell survival and tumorigenesis through protection of genetic integrity. Oncotarget 2017, 8, 5026-5037. [CrossRef] [PubMed]

23. Xiao, L.; Lanz, R.B.; Frolov, A.; Castro, P.D.; Zhang, Z.; Dong, B.; Xue, W.; Jung, S.Y.; Lydon, J.P.; Edwards, D.P. The germ cell gene TDRD1 as an ERG target gene and a novel prostate cancer biomarker. Prostate 2016, 76, 1271-1284. [CrossRef] [PubMed]

24. Schudrowitz, N.; Takagi, S.; Wessel, G.M.; Yajima, M. Germline factor DDX 4 functions in blood-derived cancer cell phenotypes. Cancer Sci. 2017, 108, 1612-1619. [CrossRef] [PubMed]

25. Lim, S.L.; Ricciardelli, C.; Oehler, M.K.; De Arao Tan, I.M.D.; Russell, D.; Grützner, F. Overexpression of piRNA Pathway Genes in Epithelial Ovarian Cancer. PLoS ONE 2014, 9, e99687. [CrossRef]

26. Wang, Q.-E.; Han, C.; Milum, K.; Wani, A.A. Stem cell protein Piwil2 modulates chromatin modifications upon cisplatin treatment. Mutat. Res. Fundam. Mol. Mech. Mutagenesis 2011, 708, 59-68. [CrossRef]

27. Hirakata, S.; Siomi, M.C. piRNA biogenesis in the germline: From transcription of piRNA genomic sources to piRNA maturation. Biochim. Biophys. Acta (BBA) Gene Regul. Mech. 2016, 1859, 82-92. [CrossRef]

28. Ozata, D.M.; Gainetdinov, I.; Zoch, A.; O'Carroll, D.; Zamore, P.D. PIWI-interacting RNAs: Small RNAs with big functions. Nat. Rev. Genet. 2019, 20, 89-108. [CrossRef]

29. Aravin, A.; Gaidatzis, D.; Pfeffer, S.; Lagos-Quintana, M.; Landgraf, P.; Iovino, N.; Morris, P.; Brownstein, M.J.; Kuramochi-Miyagawa, S.; Nakano, T. A novel class of small RNAs bind to MILI protein in mouse testes. Nature 2006, 442, 203-207. [CrossRef]

30. Iwasaki, Y.W.; Siomi, M.C.; Siomi, H. PIWI-Interacting RNA: Its Biogenesis and Functions. Annu. Rev. Biochem. 2015, 84, 405433. [CrossRef]

31. Cora, E.; Pandey, R.R.; Xiol, J.; Taylor, J.; Sachidanandam, R.; McCarthy, A.A.; Pillai, R.S. The MID-PIWI module of Piwi proteins specifies nucleotide- and strand-biases of piRNAs. RNA 2014, 20, 773-781. [CrossRef]

32. Bamezai, S.; Rawat, V.P.S.; Buske, C. Concise Review: The Piwi-piRNA Axis: Pivotal Beyond Transposon Silencing. Stem Cells 2012, 30, 2603-2611. [CrossRef] [PubMed]

33. Simon, B.; Kirkpatrick, J.P.; Eckhardt, S.; Reuter, M.; Rocha, E.A.; Andrade-Navarro, M.A.; Sehr, P.; Pillai, R.S.; Carlomagno, T. Recognition of 2'-O-methylated 3'-end of piRNA by the PAZ domain of a Piwi protein. Structure 2011, 19, 172-180. [CrossRef] [PubMed]

34. Aravin, A.A.; Sachidanandam, R.; Girard, A.; Fejes-Toth, K.; Hannon, G.J. Developmentally Regulated piRNA Clusters Implicate MILI in Transposon Control. Science 2007, 316, 744-747. [CrossRef] [PubMed]

35. Brennecke, J.; Aravin, A.A.; Stark, A.; Dus, M.; Kellis, M.; Sachidanandam, R.; Hannon, G.J. Discrete Small RNA-Generating Loci as Master Regulators of Transposon Activity in Drosophila. Cell 2007, 128, 1089-1103. [CrossRef]

36. Siomi, M.C.; Sato, K.; Pezic, D.; Aravin, A.A. PIWI-interacting small RNAs: The vanguard of genome defence. Nat. Rev. Mol. Cell Biol. 2011, 12, 246-258. [CrossRef]

37. Soper, S.F.C.; van der Heijden, G.W.; Hardiman, T.C.; Goodheart, M.; Martin, S.L.; de Boer, P.; Bortvin, A. Mouse Maelstrom, a component of nuage, is essential for spermatogenesis and transposon repression in meiosis. Dev. Cell 2008, 15, 285-297. [CrossRef]

38. Sienski, G.; Dönertas, D.; Brennecke, J. Transcriptional Silencing of Transposons by Piwi and Maelstrom and Its Impact on Chromatin State and Gene Expression. Cell 2012, 151, 964-980. [CrossRef]

39. Lim, S.L.; Qu, Z.P.; Kortschak, R.D.; Lawrence, D.M.; Geoghegan, J.; Hempfling, A.-L.; Bergmann, M.; Goodnow, C.C.; Ormandy, C.J.; Wong, L.; et al. HENMT1 and piRNA Stability Are Required for Adult Male Germ Cell Transposon Repression and to Define the Spermatogenic Program in the Mouse. PLoS Genet. 2015, 11, e1005620. [CrossRef]

40. Mani, S.R.; Juliano, C.E. Untangling the web: The diverse functions of the PIWI/piRNA pathway. Mol. Reprod. Dev. 2013, 80, 632-664. [CrossRef]

41. Sato, K.; Siomi, M.C. The piRNA pathway in Drosophila ovarian germ and somatic cells. Proc. Jpn. Acad. Ser. B 2020, 96, 32-42. [CrossRef] 
42. Ng, K.W.; Anderson, C.; Marshall, E.A.; Minatel, B.C.; Enfield, K.S.S.; Saprunoff, H.L.; Lam, W.L.; Martinez, V.D. Piwi-interacting RNAs in cancer: Emerging functions and clinical utility. Mol. Cancer 2016, 15, 5. [CrossRef] [PubMed]

43. Liu, Y.; Dou, M.; Song, X.; Dong, Y.; Liu, S.; Liu, H.; Tao, J.; Li, W.; Yin, X.; Xu, W. The emerging role of the piRNA/piwi complex in cancer. Mol. Cancer 2019, 18, 123. [CrossRef] [PubMed]

44. Tan, Y.; Liu, L.; Liao, M.; Zhang, C.; Hu, S.; Zou, M.; Gu, M.; Li, X. Emerging roles for PIWI proteins in cancer. Acta Biochim. Biophys. Sin. 2015, 47, 315-324. [CrossRef] [PubMed]

45. Xiao, L.; Wang, Y.; Zhou, Y.; Sun, Y.; Sun, W.; Wang, L.; Zhou, C.; Zhou, J.; Zhang, J. Identification of a novel human cancer/testis gene MAEL that is regulated by DNA methylation. Mol. Biol. Rep. 2010, 37, 2355-2360. [CrossRef] [PubMed]

46. Babatunde, K.A.; Najafi, A.; Salehipour, P.; Modarressi, M.H.; Mobasheri, M.B. Cancer/Testis genes in relation to sperm biology and function. Iran. J. Basic Med. Sci. 2017, 20, 967-974. [CrossRef] [PubMed]

47. Liu, L.; Dai, Y.; Chen, J.; Zeng, T.; Li, Y.; Chen, L.; Zhu, Y.H.; Li, J.; Ma, S.; Xie, D. Maelstrom promotes hepatocellular carcinoma metastasis by inducing epithelial-mesenchymal transition by way of Akt/GSK-3ß/Snail signaling. Hepatology 2014, 59, 531-543. [CrossRef]

48. Fite, K. Dysregulation of Phospholipase D (PLD) Isoforms Increases Breast Cancer Cell Invasion; Wright State University: Dayton, OH, USA, 2017.

49. Boormans, J.L.; Korsten, H.; Ziel-van der Made, A.J.; van Leenders, G.J.; de Vos, C.V.; Jenster, G.; Trapman, J. Identification of TDRD1 as a direct target gene of ERG in primary prostate cancer. Int. J. Cancer 2013, 133, 335-345. [CrossRef]

50. Ye, Y.; Yin, D.-T.; Chen, L.; Zhou, Q.; Shen, R.; He, G.; Yan, Q.; Tong, Z.; Issekutz, A.C.; Shapiro, C.L.; et al. Identification of Piwil2-Like (PL2L) Proteins that Promote Tumorigenesis. PLoS ONE 2010, 5, e13406. [CrossRef]

51. Linder, P. Dead-box proteins: A family affair-Active and passive players in RNP-remodeling. Nucleic Acids Res. 2006, 34, 4168-4180. [CrossRef]

52. Horwich, M.D.; Li, C.; Matranga, C.; Vagin, V.; Farley, G.; Wang, P.; Zamore, P.D. The Drosophila RNA Methyltransferase, DmHen1, Modifies Germline piRNAs and Single-Stranded siRNAs in RISC. Curr. Biol. 2007, 17, 1265-1272. [CrossRef]

53. Findley, S.D.; Tamanaha, M.; Clegg, N.J.; Ruohola-Baker, H. Maelstrom, a Drosophila spindle-class gene, encodes a protein that colocalizes with Vasa and RDE1/AGO1 homolog, Aubergine, in nuage. Development 2003, 130, 859-871. [CrossRef] [PubMed]

54. Gomez-Cambronero, J. Phospholipase D in cell signaling: From a myriad of cell functions to cancer growth and metastasis. J. Biol. Chem. 2014, 289, 22557-22566. [CrossRef] [PubMed]

55. Chen, C.; Nott, T.J.; Jin, J.; Pawson, T. Deciphering arginine methylation: Tudor tells the tale. Nat. Rev. Mol. Cell Biol. 2011, 12, 629-642. [CrossRef] [PubMed]

56. Jiang, L.; Wang, W.-J.; Li, Z.-W.; Wang, X.-Z. Downregulation of Piwil3 suppresses cell proliferation, migration and invasion in gastric cancer. Cancer Biomark. 2017, 20, 499-509. [CrossRef] [PubMed]

57. Yang, Y.; Zhang, X.; Song, D.; Wei, J. Piwil2 modulates the invasion and metastasis of prostate cancer by regulating the expression of matrix metalloproteinase-9 and epithelial-mesenchymal transitions. Oncol. Lett. 2015, 10, 1735-1740. [CrossRef]

58. Wang, X.; Tong, X.; Gao, H.; Yan, X.; Xu, X.; Sun, S.; Wang, Q.; Wang, J. Silencing HIWI suppresses the growth, invasion and migration of glioma cells. Int. J. Oncol. 2014, 45, 2385-2392. [CrossRef] [PubMed]

59. Kim, K.H.; Kang, Y.-J.; Jo, J.-O.; Ock, M.S.; Moon, S.H.; Suh, D.S.; Yoon, M.S.; Park, E.-S.; Jeong, N.; Eo, W.-K. DDX4 (DEAD box polypeptide 4) colocalizes with cancer stem cell marker CD133 in ovarian cancers. Biochem. Biophys. Res. Commun. 2014, 447, 315-322. [CrossRef]

60. Hashimoto, H.; Sudo, T.; Mikami, Y.; Otani, M.; Takano, M.; Tsuda, H.; Itamochi, H.; Katabuchi, H.; Ito, M.; Nishimura, R. Germ cell specific protein VASA is over-expressed in epithelial ovarian cancer and disrupts DNA damage-induced G2 checkpoint. Gynecol. Oncol. 2008, 111, 312-319. [CrossRef]

61. Guijo, M.; Ceballos-Chávez, M.; Gómez-Marín, E.; Basurto-Cayuela, L.; Reyes, J.C. Expression of TDRD9 in a subset of lung carcinomas by CpG island hypomethylation protects from DNA damage. Oncotarget 2017, 9, 9618-9631. [CrossRef]

62. Li, J.; Xu, L.; Bao, Z.; Xu, P.; Chang, H.; Wu, J.; Bei, Y.; Xia, L.; Wu, P.; Cui, G. High expression of PIWIL2 promotes tumor cell proliferation, migration and predicts a poor prognosis in glioma. Oncol. Rep. 2017, 38, 183-192. [CrossRef]

63. Gainetdinov, I.V.; Kondratieva, S.A.; Skvortsova, Y.V.; Zinovyeva, M.V.; Stukacheva, E.A.; Klimov, A.; Tryakin, A.A.; Azhikina, T.L. Distinguishing epigenetic features of preneoplastic testis tissues adjacent to seminomas and nonseminomas. Oncotarget 2016, 7, 22439. [CrossRef]

64. Iliev, R.; Stanik, M.; Fedorko, M.; Poprach, A.; Vychytilova-Faltejskova, P.; Slaba, K.; Svoboda, M.; Fabian, P.; Pacik, D.; Dolezel, J. Decreased expression levels of PIWIL1, PIWIL2, and PIWIL4 are associated with worse survival in renal cell carcinoma patients. Oncotargets Ther. 2016, 9, 217.

65. Cheng, J.; Deng, H.; Xiao, B.; Zhou, H.; Zhou, F.; Shen, Z.; Guo, J. piR-823, a novel non-coding small RNA, demonstrates in vitro and in vivo tumor suppressive activity in human gastric cancer cells. Cancer Lett. 2012, 315, 12-17. [CrossRef] [PubMed]

66. Yan, H.; Wu, Q.; Sun, C.; Ai, L.; Deng, J.; Zhang, L.; Chen, L.; Chu, Z.; Tang, B.; Wang, K. piRNA-823 contributes to tumorigenesis by regulating de novo DNA methylation and angiogenesis in multiple myeloma. Leukemia 2015, 29, 196-206. [CrossRef] [PubMed]

67. Cheng, J.; Guo, J.-M.; Xiao, B.-X.; Miao, Y.; Jiang, Z.; Zhou, H.; Li, Q.-N. piRNA, the new non-coding RNA, is aberrantly expressed in human cancer cells. Clin. Chim. Acta 2011, 412, 1621-1625. [CrossRef] [PubMed] 
68. Palma Flores, C.; García-Vázquez, R.; Gallardo Rincón, D.; Ruiz-García, E.; Astudillo de la Vega, H.; Marchat, L.A.; Salinas Vera, Y.M.; López-Camarillo, C. MicroRNAs driving invasion and metastasis in ovarian cancer: Opportunities for translational medicine. Int. J. Oncol. 2017, 50, 1461-1476. [CrossRef] [PubMed]

69. Law, P.T.-Y.; Qin, H.; Ching, A.K.-K.; Lai, K.P.; Co, N.N.; He, M.; Lung, R.W.-M.; Chan, A.W.-H.; Chan, T.-F.; Wong, N. Deep sequencing of small RNA transcriptome reveals novel non-coding RNAs in hepatocellular carcinoma. J. Hepatol. 2013, 58, 1165-1173. [CrossRef]

70. Liu, X.; Zheng, J.; Xue, Y.; Yu, H.; Gong, W.; Wang, P.; Li, Z.; Liu, Y. PIWIL3/OIP5-AS1/miR-367-3p/CEBPA feedback loop regulates the biological behavior of glioma cells. Theranostics 2018, 8, 1084-1105. [CrossRef]

71. von Eyss, B.; Jaenicke, L.A.; Kortlever, R.M.; Royla, N.; Wiese, K.E.; Letschert, S.; McDuffus, L.-A.; Sauer, M.; Rosenwald, A.; Evan, G.I.; et al. A MYC-Driven Change in Mitochondrial Dynamics Limits YAP/TAZ Function in Mammary Epithelial Cells and Breast Cancer. Cancer Cell 2015, 28, 743-757. [CrossRef]

72. Hempfling, A.-L.; Lim, S.L.; Adelson, D.; Evans, J.; O'Connor, A.E.; Qu, Z.; Kliesch, S.; Weidner, W.; O’Bryan, M.; Bergmann, M. Expression patterns of HENMT1 and PIWIL1 in human testis-Implications for transposon expression. Reproduction 2017, 154, 363-374. [CrossRef]

73. Iorio, M.V.; Visone, R.; Di Leva, G.; Donati, V.; Petrocca, F.; Casalini, P.; Taccioli, C.; Volinia, S.; Liu, C.-G.; Alder, H. MicroRNA signatures in human ovarian cancer. Cancer Res. 2007, 67, 8699-8707. [CrossRef] [PubMed]

74. Kacprzyk, L.A.; Laible, M.; Andrasiuk, T.; Brase, J.C.; Börno, S.T.; Fälth, M.; Kuner, R.; Lehrach, H.; Schweiger, M.R.; Sültmann, H. ERG Induces Epigenetic Activation of Tudor Domain-Containing Protein 1 (TDRD1) in ERG Rearrangement-Positive Prostate Cancer. PLoS ONE 2013, 8, e59976. [CrossRef] [PubMed]

75. Gambichler, T.; Kohsik, C.; Höh, A.-K.; Lang, K.; Käfferlein, H.U.; Brüning, T.; Stockfleth, E.; Stücker, M.; Dreißigacker, M.; Sand, M. Expression of PIWIL3 in primary and metastatic melanoma. J. Cancer Res. Clin. Oncol. 2017, 143, 433-437. [CrossRef] [PubMed]

76. Li, W.; Martinez-Useros, J.; Garcia-Carbonero, N.; Fernandez-Aceñero, M.J.; Orta, A.; Ortega-Medina, L.; Garcia-Botella, S.; PerezAguirre, E.; Diez-Valladares, L.; Celdran, A.; et al. The Clinical Significance of PIWIL3 and PIWIL4 Expression in Pancreatic Cancer. J. Clin. Med. 2020, 9, 1252. [CrossRef] [PubMed]

77. Tan, M.; van Tol, H.T.; Rosenkranz, D.; Roovers, E.F.; Damen, M.J.; Stout, T.A.; Wu, W.; Roelen, B.A. PIWIL3 forms a complex with TDRKH in mammalian oocytes. Cells 2020, 9, 1356. [CrossRef] [PubMed]

78. Salomon-Perzyński, A.; Salomon-Perzyńska, M.; Michalski, B.; Skrzypulec-Plinta, V. High-grade serous ovarian cancer: The clone wars. Arch. Gynecol. Obstet. 2017, 295, 569-576. [CrossRef]

79. Birkbak, N.J.; Eklund, A.C.; Li, Q.; McClelland, S.E.; Endesfelder, D.; Tan, P.; Tan, I.B.; Richardson, A.L.; Szallasi, Z.; Swanton, C. Paradoxical relationship between chromosomal instability and survival outcome in cancer. Cancer Res. 2011, 71, 3447-3452. [CrossRef]

80. Öner, Ç.; Turgut Coşan, D.; Çolak, E. Estrogen and Androgen Hormone Levels Modulate the Expression of PIWI Interacting RNA in Prostate and Breast Cancer. PLoS ONE 2016, 11, e0159044. [CrossRef]

81. Wang, H.; Wang, B.; Liu, J.; Li, A.; Zhu, H.; Wang, X.; Zhang, Q. Piwil1 gene is regulated by hypothalamic-pituitary-gonadal axis in turbot (Scophthalmus maximus): A different effect in ovaries and testes. Gene 2018, 658, 86-95. [CrossRef]

82. Zhang, D.; Duarte-Guterman, P.; Langlois, V.S.; Trudeau, V.L. Temporal expression and steroidal regulation of piRNA pathway genes (mael, piwi, vasa) during Silurana (Xenopus) tropicalis embryogenesis and early larval development. Comp. Biochem. Physiol. Part C Toxicol. Pharmacol. 2010, 152, 202-206. [CrossRef]

83. Zhou, Y.; Zhong, H.; Liu, S.; Yu, F.; Hu, J.; Zhang, C.; Tao, M.; Liu, Y. Elevated expression of Piwi and piRNAs in ovaries of triploid crucian carp. Mol. Cell. Endocrinol. 2014, 383, 1-9. [CrossRef] [PubMed]

84. Pan, Y.; Hu, M.; Liang, H.; Wang, J.-J.; Tang, L.-J. The expression of the PIWI family members miwi and mili in mice testis is negatively affected by estrogen. Cell Tissue Res. 2012, 350, 177-181. [CrossRef] [PubMed]

85. Lee, E.; University of Adelaide, Adelaide, South Australia, Australia. Personal communication, 2020.

86. Zheng, W.; Lu, J.J.; Luo, F.; Zheng, Y.; Feng, Y.-J.; Felix, J.C.; Lauchlan, S.C.; Pike, M.C. Ovarian Epithelial Tumor Growth Promotion by Follicle-Stimulating Hormone and Inhibition of the Effect by Luteinizing Hormone. Gynecol. Oncol. 2000, 76, 80-88. [CrossRef]

87. Syed, V.; Ulinski, G.; Mok, S.C.; Ho, S.-M. Reproductive hormone-induced, STAT3-mediated interleukin 6 action in normal and malignant human ovarian surface epithelial cells. J. Natl. Cancer Inst. 2002, 94, 617-629. [CrossRef]

88. Li, D.; Sun, X.; Yan, D.; Huang, J.; Luo, Q.; Tang, H.; Peng, Z. Piwil2 modulates the proliferation and metastasis of colon cancer via regulation of matrix metallopeptidase 9 transcriptional activity. Exp. Biol. Med. 2012, 237, 1231-1240. [CrossRef] [PubMed]

89. Lee, J.H.; Jung, C.; Javadian-Elyaderani, P.; Schweyer, S.; Schütte, D.; Shoukier, M.; Karimi-Busheri, F.; Weinfeld, M.; RasouliNia, A.; Hengstler, J.G.; et al. Pathways of Proliferation and Antiapoptosis Driven in Breast Cancer Stem Cells by Stem Cell Protein Piwil2. Cancer Res. 2010, 70, 4569-4579. [CrossRef] [PubMed]

90. Zhang, D.; Wu, X.; Liu, X.; Cai, C.; Zeng, G.; Rohozinski, J.; Zhang, Y.; Wei, G.; He, D. Piwil2-transfected human fibroblasts are cancer stem cell-like and genetically unstable. Oncotarget 2017, 8, 12259. [CrossRef]

91. Zhang, Z.; Zhu, Y.; Lai, Y.; Wu, X.; Feng, Z.; Yu, Y.; Bast, R.C.; Wan, X.; Xi, X.; Feng, Y. Follicle-stimulating hormone inhibits apoptosis in ovarian cancer cells by regulating the OCT4 stem cell signaling pathway. Int. J. Oncol. 2013, 43, 1194-1204. [CrossRef]

92. Gera, S.; Kumar, S.S.; Swamy, S.N.; Bhagat, R.; Vadaparty, A.; Gawari, R.; Bhat, R.; Dighe, R.R. Follicle-Stimulating Hormone Is an Autocrine Regulator of the Ovarian Cancer Metastatic Niche Through Notch Signaling. J. Endocr. Soc. 2018, 3, 340-357. [CrossRef]

93. Feng, D.; Zhao, T.; Yan, K.; Liang, H.; Liang, J.; Zhou, Y.; Zhao, W.; Ling, B. Gonadotropins promote human ovarian cancer cell migration and invasion via a cyclooxygenase 2-dependent pathway. Oncol. Rep. 2017, 38, 1091. [CrossRef] 
94. Mertens-Walker, I.; Bolitho, C.; Baxter, R.C.; Marsh, D.J. Gonadotropin-induced ovarian cancer cell migration and proliferation require extracellular signal-regulated kinase $1 / 2$ activation regulated by calcium and protein kinase C $\delta$. Endocr. Relat. Cancer 2010, 17, 335. [CrossRef] [PubMed]

95. Song, K.; Dai, L.; Long, X.; Wang, W.; Di, W. Follicle-stimulating hormone promotes the proliferation of epithelial ovarian cancer cells by activating sphingosine kinase. Sci. Rep. 2020, 10, 1-13. [CrossRef] [PubMed]

96. Ivarsson, K.; Sundfeldt, K.; Brännström, M.; Hellberg, P.R.; Janson, P.O. Diverse effects of FSH and LH on proliferation of human ovarian surface epithelial cells. Hum. Reprod. 2001, 16, 18-23. [CrossRef] [PubMed]

97. Bourgeois, D.L.; Kabarowski, K.A.; Porubsky, V.L.; Kreeger, P.K. High-grade serous ovarian cancer cell lines exhibit heterogeneous responses to growth factor stimulation. Cancer Cell Int. 2015, 15, 112. [CrossRef]

98. Chen, Z.; Che, Q.; He, X.; Wang, F.; Wang, H.; Zhu, M.; Sun, J.; Wan, X. Stem cell protein Piwil1 endowed endometrial cancer cells with stem-like properties via inducing epithelial-mesenchymal transition. BMC Cancer 2015, 15, 811. [CrossRef]

99. Li, C.; Zhou, X.; Chen, J.; Lu, Y.; Sun, Q.; Tao, D.; Hu, W.; Zheng, X.; Bian, S.; Liu, Y.; et al. PIWIL1 destabilizes microtubule by suppressing phosphorylation at Ser16 and RLIM-mediated degradation of stathmin1. Oncotarget 2015, 6, 27794-27804. [CrossRef]

100. Qu, X.; Liu, J.; Zhong, X.; Li, X.; Zhang, Q. PIWIL2 promotes progression of non-small cell lung cancer by inducing CDK2 and Cyclin A expression. J. Transl. Med. 2015, 13, 301. [CrossRef]

101. Jiang, S.; Zhao, L.; Lu, Y.; Wang, M.; Chen, Y.; Tao, D.; Liu, Y.; Sun, H.; Zhang, S.; Ma, Y. Piwil2 inhibits keratin 8 degradation through promoting p38-induced phosphorylation to resist Fas-mediated apoptosis. Mol. Cell. Biol. 2014, 34, 3928-3938. [CrossRef]

102. Lu, Y.; Zhang, K.; Li, C.; Yao, Y.; Tao, D.; Liu, Y.; Zhang, S.; Ma, Y. Piwil2 Suppresses P53 by Inducing Phosphorylation of Signal Transducer and Activator of Transcription 3 in Tumor Cells. PLoS ONE 2012, 7, e30999. [CrossRef]

103. Lokman, N.A.; Price, Z.K.; Hawkins, E.K.; Macpherson, A.M.; Oehler, M.K.; Ricciardelli, C. 4-Methylumbelliferone Inhibits Cancer Stem Cell Activation and Overcomes Chemoresistance in Ovarian Cancer. Cancers 2019, 11, 1187. [CrossRef]

104. Tan, T.Z.; Yang, H.; Ye, J.; Low, J.; Choolani, M.; Tan, D.S.P.; Thiery, J.-P.; Huang, R.Y.-J. CSIOVDB: A microarray gene expression database of epithelial ovarian cancer subtype. Oncotarget 2015, 6, 43843. [CrossRef] [PubMed]

105. Győrffy, B.; Lánczky, A.; Szállási, Z. Implementing an online tool for genome-wide validation of survival-associated biomarkers in ovarian-cancer using microarray data from 1287 patients. Endocr. Relat. Cancer 2012, 19, 197-208. [CrossRef] [PubMed]

106. Lokman, N.A.; Elder, A.S.F.; Ricciardelli, C.; Oehler, M.K. Chick Chorioallantoic Membrane (CAM) Assay as an In Vivo Model to Study the Effect of Newly Identified Molecules on Ovarian Cancer Invasion and Metastasis. Int. J. Mol. Sci. 2012, 13, 99599970. [CrossRef] [PubMed] 